\title{
PERFORMANCE OF STATISTICAL DOWNSCALING MODELS IN GCM VALIDATION AND REGIONAL CLIMATE CHANGE ESTIMATES: APPLICATION FOR SWEDISH PRECIPITATION
}

\author{
ARISTITA BUSUIOC ${ }^{\mathrm{a}, \mathrm{b}}$, DELIANG CHEN ${ }^{\mathrm{a}, *}$ and CECILIA HELLSTRÖM ${ }^{\mathrm{a}}$ \\ a Department of Earth Sciences, Göteborg University, Sweden \\ ${ }^{\mathrm{b}}$ National Institute of Meteorology and Hydrology, Bucharest, Romania \\ Received 24 March 2000 \\ Revised 18 October 2000 \\ Accepted 18 October 2000 \\ Published online 3 April 2001
}

\begin{abstract}
This study deals with an analysis of the performance of a general circulation model (GCM) (HadCM2) in reproducing the large-scale circulation mechanisms controlling Swedish precipitation variability, and in estimating regional climate changes owing to increased $\mathrm{CO}_{2}$ concentration by using canonical correlation analysis (CCA). Seasonal precipitation amounts at 33 stations in Sweden over the period 1899-1990 are used. The large-scale circulation is represented by sea level pressure (SLP) over the Atlantic-European region.

The link between seasonal Swedish precipitation and large-scale SLP variability is strong in all seasons, but especially in winter and autumn. For these two seasons, the link is a consequence of the North Atlantic Oscillation (NAO) pattern. In winter, another important mechanism is related to a cyclonic/anticyclonic structure centred over southern Scandinavia. In the past century, this connection has remained almost unchanged in time for all seasons except spring. The downscaling model that is built on the basis of this link is skilful in all seasons, but especially so in winter and autumn. This observed link is only partially reproduced by the HadCM2 model, while large-scale SLP variability is fairly well reproduced in all seasons. A concept about optimum statistical downscaling models for climate change purposes is proposed. The idea is related to the capability of the statistical downscaling model to reproduce low frequency variability, rather than having the highest skill in terms of explained variance. By using these downscaling models, it was found that grid point and downscaled climate signals are similar (increasing precipitation) in summer and autumn, while in winter, the amplitudes of the two signals are different. In spring, both signals show a slight increase in the northern and southern parts of Sweden. Copyright (C) 2001 Royal Meteorological Society.

KEY WORDS: statistical downscaling; HadCM2; CCA; EOF; precipitation; Sweden
\end{abstract}

\section{INTRODUCTION}

Precipitation is one of the most frequently used climate variables in impact studies on climate change. General circulation models (GCMs) are the best available tools to estimate future global climate changes owing to the continuing increase of greenhouse gas concentration in the atmosphere. These models are currently integrated over coarse spatial scales, which are larger than the spatial scale of most atmospheric processes controlling precipitation. The GCMs are able to simulate fairly well the most important mean features on large scales. Typically, GCMs are better at simulating upper-air fields than surface climate variables. Among surface climate variables, large-scale sea level pressure (SLP) is usually better simulated, while for the others, such as temperature and precipitation, GCMs have much smaller skill (Karl et al., 1990; Palutikof et al., 1997). Because of some uncertainty in the modelling of precipitation, it is first important to assess how well a GCM simulates the present-day precipitation at various space and time-scales (Palutikof et al., 1997). Second, there is often a need (e.g. from agriculture and water

* Correspondence to: Department of Earth Sciences, Göteborg University, Box 460, 40530 Göteborg, Sweden; e-mail: deliang@gvc.gu.se

Copyright (C) 2001 Royal Meteorological Society 
management) to provide climate variables at a finer spatial resolution than these models can supply (von Storch, 1995b).

A number of difficulties arise when a GCM is assessed against observations. First, the spatial scales represented by GCMs and point measurements are different. Other problems are the selection of the reference period (to compare observed climate with simulated climate) and length of GCM control runs available. Parameterizations of various sub-grid scale processes are often made from different available observed periods. Moreover, the current climate period chosen for comparison with the GCM control run must be homogeneous over a long enough period (e.g. does not contain any trends or shifts in the observed variable), which is rare.

There are various GCM validation methods. First, the area average/spatial distribution of long-term mean for various variables computed from observed data and GCM simulations can be directly compared (Hulme, 1994; Ponater et al., 1994; Cubasch et al., 1996). In this way, the ability of the GCM in reproducing the climatology can be evaluated. Other methods involve analyses of the main features of the spatial variability (usually given by the most important empirical orthogonal function (EOF) patterns), and large-scale mechanisms controlling the regional climate variability given by the canonical correlation analysis (CCA) (von Storch et al., 1993; Ponater et al., 1994; Kharin, 1995; Busuioc et al., 1999a).

Two kinds of methods (dynamical and statistical) of translating the large-scale information to smaller scale, commonly referred to as downscaling, are used, each of them having its disadvantages and advantages (von Storch, 1995b; Zorita and von Storch, 1999). The dynamical approaches have been directed in two directions. One of them consists in improving of the GCM horizontal resolution up to T106 (about $1.125^{\circ}$ ). Unfortunately, these simulations are quite costly, and for climate change estimation, the applications so far have been restricted to the 'time slice modus' (Bengtsson et al., 1995) which uses an atmospheric high-resolution model forced by the mean boundary conditions simulated in a low-resolution atmosphere-ocean coupled model. Another direction is given by the limited area models (LAMs) that are 'nested' within a GCM (Giorgi and Mearns, 1991). This technique, initially used for numerical weather prediction, and then adapted for regional climate studies, presents some inconvenience, given by the fact that the abrupt change of grid size at the lateral boundaries can distort wave propagation and reflection properties. Other studies show that incoming flow is more effectively represented by gradually changing resolution, rather than through an abrupt resolution change (Fox-Rabinovitz et al., 1997). Even if the LAMs seem to be the best tool in the future to estimate reliable regional climate changes, they still need improvements in order to reduce the local systematic model errors (Machenhauer et al., 1998; Rummukainen et al., 1998).

The statistical downscaling approach is sometimes preferred, mainly because of its relative ease to use and lower cost compared with the use of LAMs. Statistical downscaling searches for a statistical relationship between predictands (small-scale variables) and predictors (large-scale variables well simulated by GCMs). These approaches vary in temporal/spatial scales and statistical techniques. A recent review of currently used techniques is presented by Zorita and von Storch (1999).

Among statistical techniques, linear methods are frequently used: simple or multivariate regression (Chen and Chen, 1999), CCA (Karl et al., 1990; Wigley et al., 1990; von Storch et al., 1993; Busuioc et al., 1999a), and singular value decomposition (SVD; Benestad, 1998). Non-linear approaches, such as neural networks (Cavazos, 1999; Zorita and von Storch, 1999) and circulation classification (Goodess and Palutikof, 1998) have recently been developed. CCA has the main advantage of selecting pairs of spatial patterns that are optimally correlated, making a physical interpretation of connection between predictands and predictors possible. Because of this advantage, this method is also used as a GCM validation method (Noguer, 1994; Busuioc et al., 1999a), and will also be used in this work.

Generally, any successful statistical downscaling should satisfy three main conditions: (i) the link between predictands and predictors has to be strong in order to explain satisfactorily the local climate variability; (ii) the predictor variable should be well simulated by the GCM; and (iii) the relationship between predictands and predictors should not change in time, and should remain the same in a changed future climate. Concerning the third condition, only the stability of the relationship in the present climate can be verified. For the future climate, this assumption is generally taken to be valid. A method to verify 
the applicability of empirical downscaling procedure in a changed climate has been proposed by Busuioc et al. (1999a), and will be used in this work. An additional rule for selecting the optimal statistical downscaling model is also proposed here.

The objectives of this work are: (1) to establish links between large-scale circulation patterns and regional precipitation in Sweden; (2) to develop optimal statistical downscaling models based on the established links; (3) to validate the GCM used in terms of its ability to reproduce the observed SLP and precipitation patterns and the established empirical links; and (4) to create climate change scenarios using skilful GCM simulation and optimal statistical models.

Section 2 presents the data and methods used in this study. The results are given in Section 3, and Section 4 summarizes the conclusions.

\section{DATA AND METHODS}

Observational data used in this study are monthly precipitation in Sweden at 33 stations and monthly mean SLP over the North Atlantic and European region over the interval 1899-1990. All the precipitation data have been carefully examined, and some of them corrected and homogenized through the North Atlantic Climatological Dataset (NACD) programme (Frich et al., 1996). The names and positions of the stations are presented in Table I. The monthly SLP data with a resolution of $5^{\circ} \times 5^{\circ}$ were provided by the National Center of Atmospheric Research (NCAR, USA) (Trenberth and Paolino, 1980). The SLP area between $40^{\circ} \mathrm{W}-40^{\circ} \mathrm{E}$ and $40^{\circ}-70^{\circ} \mathrm{N}$ was optimally selected, so that the skill of the downscaling model (see below) is maximized when applied to an independent data set. For both precipitation and SLP, the anomalies have been computed by subtracting the long-term mean from the original values.

The GCM simulations (grid point precipitation and SLP) of the Hadley Centre coupled ocean-atmosphere GCM HadCM2 $\left(1 \times \mathrm{CO}_{2}\right.$ and $\left.2.5 \times \mathrm{CO}_{2}\right)$ experiments were also considered. A detailed description of the HadCM2 is given in Johns (1996) and Johns et al. (1997). It has a horizontal resolution of $2.5^{\circ}$ in latitude and $3.75^{\circ}$ in longitude. The model uses 19 vertical levels and 20 levels for the representation of the ocean. The ability of the model to simulate the present climate of northern Europe was evaluated by Räisänen and Döscher (1999). The 10 years of the HadCM2 integration are used in this work. CCA (Barnett and Preisendorfer, 1987; von Storch, 1995a) was used to assess how well the HadCM2 model simulates seasonal Swedish precipitation, and large-scale mechanisms controlling them. This method is also used to build the statistical downscaling model, as has been presented by Busuioc et al. (1999a). CCA selects pairs of spatial patterns of two space-time-dependent variables (the large-scale predictors and regional-scale predictands), so that their time components are optimally correlated. Prior to the CCA, the original data are projected onto their EOFs to eliminate noise (small-scale features), and to reduce the dimension of the data. As the time coefficients are normalized to unity, the canonical correlation patterns represent the typical strength of the signal. The first CCA pair gives the maximum correlation between the two parameters, followed by the second CCA pair, and so on. In this work, the first three CCA pairs, as derived from observations and from control run simulations, were retained and compared. In this way, the ability of the GCM to reproduce the main mechanisms controlling Swedish seasonal precipitation variability is evaluated. The first three EOFs of precipitation and SLP were used to see how realistically the model is able to simulate the spatial variability of regional precipitation and large-scale SLP. The EOF and CCA patterns derived for the observed data are computed for the two sub-intervals 1899-1940 and 1941-1990, in order to test if the main features of the regional precipitation and large-scale SLP, as well as the precipitation-SLP link, are stable in time.

A subset of CCA pairs is then used in a regression model to estimate the local precipitation from the large-scale SLP. The skill of the downscaling model is dependent on the number of the EOFs retained for the CCA, and the number of CCA components used in the regression model. Various alternatives are tested to select the optimum number of EOF and CCA time components. Most commonly, the optimum number of retained EOFs is determined in such a way that using one more EOF would change the 
Table I. Stations used in the analyses

\begin{tabular}{|c|c|c|c|}
\hline Station & $\phi\left({ }^{\circ} \mathrm{N}\right)$ & $\lambda\left({ }^{\circ} \mathrm{E}\right)$ & $H(\mathrm{~m})$ \\
\hline 1. Falsterbo & 55.38 & 12.82 & 5 \\
\hline 2. Halmstad & 56.67 & 12.92 & 25 \\
\hline 3. Växjö & 56.87 & 14.80 & 166 \\
\hline 4. Kalmar & 56.72 & 16.28 & 15 \\
\hline 5. Hoburg & 56.92 & 18.13 & 38 \\
\hline 6. Göteborg & 57.77 & 11.88 & 19 \\
\hline 7. Boräs & 57.77 & 12.93 & 20 \\
\hline 8. Ölands norra udde & 57.37 & 17.10 & 135 \\
\hline 9. Visby & 57.67 & 18.33 & 4 \\
\hline 10. Vänersborg & 58.20 & 12.37 & 42 \\
\hline 11. Ålberga & 58.73 & 16.55 & 50 \\
\hline 12. Landsort & 58.73 & 17.87 & 25 \\
\hline 13. Gotska Sanön & 58.38 & 19.18 & 13 \\
\hline 14. Karlstad & 59.35 & 13.47 & 12 \\
\hline 15. Lisjö & 59.70 & 16.07 & 46 \\
\hline 16. Uppsala & 59.85 & 17.62 & 60 \\
\hline 17. Stockholm & 59.33 & 18.05 & 44 \\
\hline 18. Svenska Högarna & 59.43 & 19.50 & 12 \\
\hline 19. Malung & 60.70 & 13.68 & 308 \\
\hline 20. Falun & 60.62 & 15.62 & 160 \\
\hline 21. Sveg & 62.02 & 14.35 & 360 \\
\hline 22. Sidsjö & 62.38 & 17.28 & 60 \\
\hline 23. Hörnösänd & 62.62 & 17.93 & 8 \\
\hline 24. Östersund & 63.18 & 14.48 & 376 \\
\hline 25. Junsele & 63.68 & 16.87 & 210 \\
\hline 26. Holmögadd & 63.58 & 20.75 & 6 \\
\hline 27. Lövånger & 64.37 & 21.32 & 21 \\
\hline 28. Stensele & 65.07 & 17.15 & 325 \\
\hline 29. Piteå & 65.32 & 21.48 & 6 \\
\hline 30. Haparanda & 65.82 & 24.13 & 5 \\
\hline 31. Kvikkjokk & 66.95 & 17.73 & 337 \\
\hline 32. Jokkmokk & 66.62 & 19.63 & 260 \\
\hline 33. Karesuando & 68.43 & 22.48 & 327 \\
\hline
\end{tabular}

$\phi=$ latitude, $\lambda=$ longitude, $H=$ elevation.

canonical correlations only a little (Werner and von Storch, 1993; von Storch, 1995a). Another way for the optimum choice of the number of EOFs retained in the CCA analysis and the number of CCA time components used in the regression model is to determine them simultaneously, such that the skill of the model is high, and does not change substantially after the addition of new components (Busuioc et al., 1999b). The skill (bbs) of the downscaling model is expressed through the variance (var) explained by the reconstructed local values $\left(Y^{\prime}\right)$ as a fraction from the total variance of the observed values $(Y)$ given by the relationship

$$
\text { bbs }=1-\frac{\operatorname{var}\left(Y-Y^{\prime}\right)}{\operatorname{var}(Y)}
$$

or, alternatively, by the correlation coefficient $(r)$ between observed and reconstructed values. In the present paper, the last way for finding an optimum model was used, with the additional condition that the downscaling model should be capable of reproducing the low frequency variability (e.g. general trend) in order to capture better the climate change signal. For other purposes (e.g. reconstructing of the past values) the highest skill in terms of explained variance and correlation coefficient could be the most desirable. 
The statistical relationships derived from observations are then applied to the SLP anomalies simulated under the $2.5 \times \mathrm{CO}_{2}$ conditions. The changes of precipitation at the stations are thus obtained for all seasons for which a skilful downscaling model can be obtained. It is generally accepted that there is a major caveat in any estimation of climate change, whether derived from statistical or dynamical models and this fact is owing to the parameters of these models, which are fitted to current climate conditions. In statistical downscaling models, regional variables are parameterized directly by large-scale climate variables. These parameterizations represent empirical relationships that are not known to remain valid in a changed climate. Particularly, it is a problem in downscaling applications where only a single relationship is considered (in our case SLP-precipitation relationship), possibly missing other processes determining the local variable in a changed climate like change in moisture and local climate variability. Some techniques have been proposed in order to verify the validity of the statistical downscaling relationships in a changed future climate. One of them is that presented by Busuioc et al. (1999a) comparing the downscaled climate changes with climate changes derived directly from the GCM grid points. This comparison is made when the GCM is proven to be reliable, i.e. it reproduces fairly well the most important SLP EOF patterns and the most important CCA pairs. It has to be stressed that this is not a proof that the downscaling technique can be used for a changed climate, we argue only that, if the similarities between the downscaled climate change estimates and GCM-simulated changes can be demonstrated, it is more likely that the empirical relationship remains valid. This is only an improvement in the sense of increased confidence over the mere assumption commonly made in downscaling studies that the downscaling relationship can still be used in a changed climate. Even if the GCM-simulated and downscaled regional changes are similar, it might be the case that both models are wrong for the changed climate because both the empirical parameterizations in the GCM and the single empirical relationship in the downscaling model might not be valid anymore.

\section{RESULTS}

\subsection{The links and statistical downscaling model}

The link between seasonal Swedish precipitation variability and SLP variability over the Atlantic-European region was studied over two independent intervals, 1899-1940 and 1941-1990, of the observational period; it was found that, in the past century, this connection has remained approximately unchanged in time for all seasons except spring. Figures 1 and 2 show, as an example, the first three CCA pairs over the 1899-1940 interval for winter (December, January, February (DJF)) and autumn (September, October, November (SON)), respectively. The main three atmospheric circulation mechanisms given by the first three CCA pairs controlling Swedish precipitation variability for the two seasons can be summarized as follows:

- The North Atlantic Oscillation (NAO) pattern representing the western/eastern flow is associated with positive/negative precipitation anomalies over the whole of Sweden with higher anomalies in the southwestern part (first CCA pair). The strong influence of the NAO on the European and Swedish climate was earlier described by, e.g. Hurrell (1995) and Chen and Hellström (1999).

- A cyclonic/anticyclonic structure centred generally over the British Isles is associated with positive/negative precipitation anomalies over almost the entire country with higher anomalies in the south to southeastern part. This structure includes the Baltic Sea influence upon Swedish precipitation variability. Sometimes, the centre of the SLP pattern moves or it becomes more or less extended, which leads to a regionalization of Swedish precipitation variability (compare, for example, the patterns of the second CCA pair from Figures 1 and 2).

- A dipole structure with a west-east gradient is associated with a dipole structure of Swedish precipitation anomalies, with a north-south or a west-east gradient, depending on the position and extension of the two centres (compare the patterns of the third CCA pair from Figures 1 and 2). 
Winter CCA1 1899-1940 cor:0.89 var:28\%

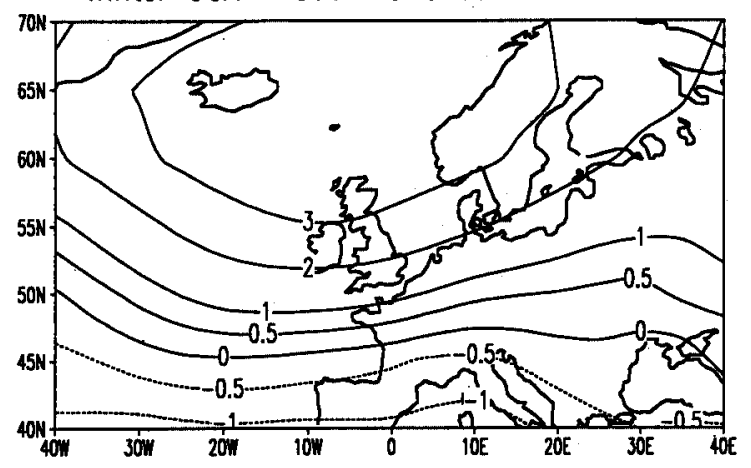

CCA2 cor: 0.88 var: $25 \%$

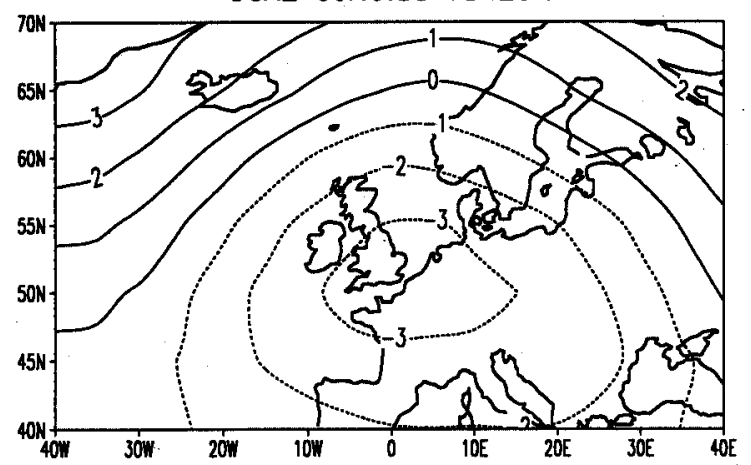

CCA3 cor: 0.54 var: $24 \%$

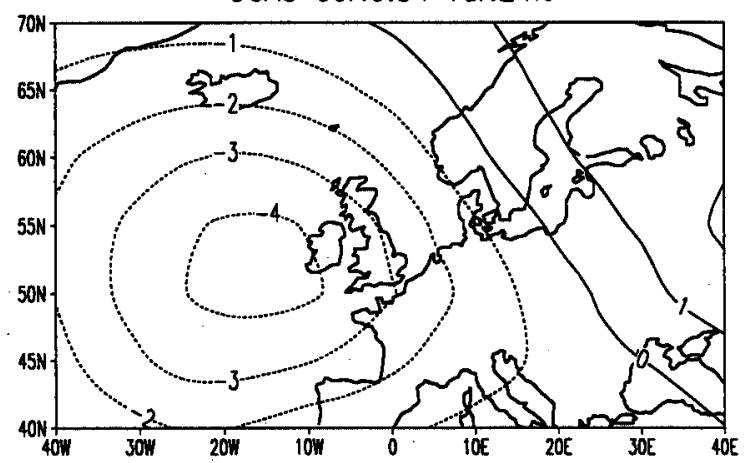

CCA1 28\%

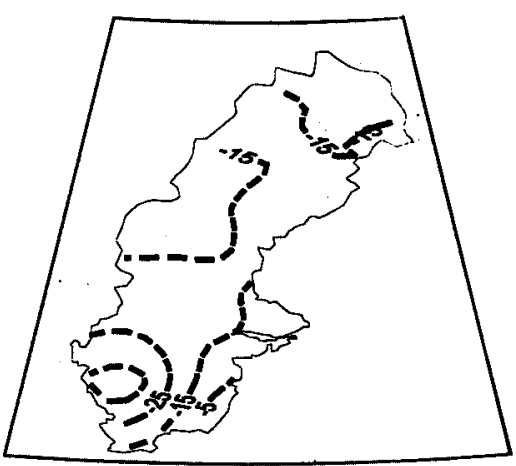

CCA2 29\%

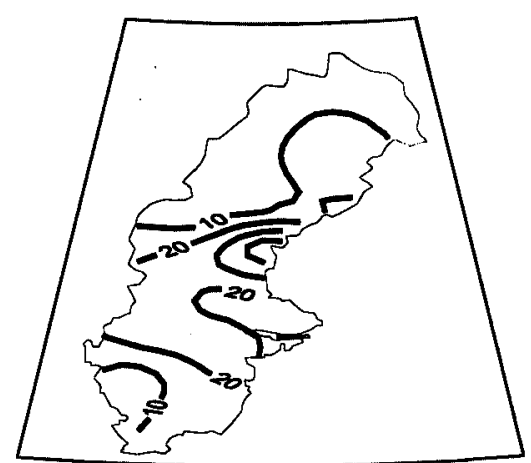

$\operatorname{CCA} 35 \%$

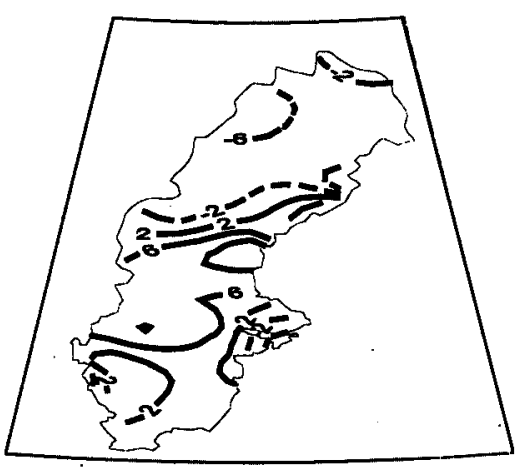

Figure 1. The patterns of the first three CCA pairs of winter mean SLP (left) and winter total precipitation (right) in Sweden as derived from observation (1899-1940)

The importance of the circulation patterns involved in Swedish precipitation variability presented above (given by the canonical correlation coefficient and explained variance of the CCA patterns) varies with season. During winter, the first two circulation mechanisms are equally important, while during autumn, the first mechanism is much more important. For the other seasons (not shown) the circulation patterns vary according to their importance/intensity or other mechanisms are noted. For spring (March, April, May (MAM)) the first CCA pair (canonical correlation coefficient $r$ is 0.77 ) is quite similar to the first 

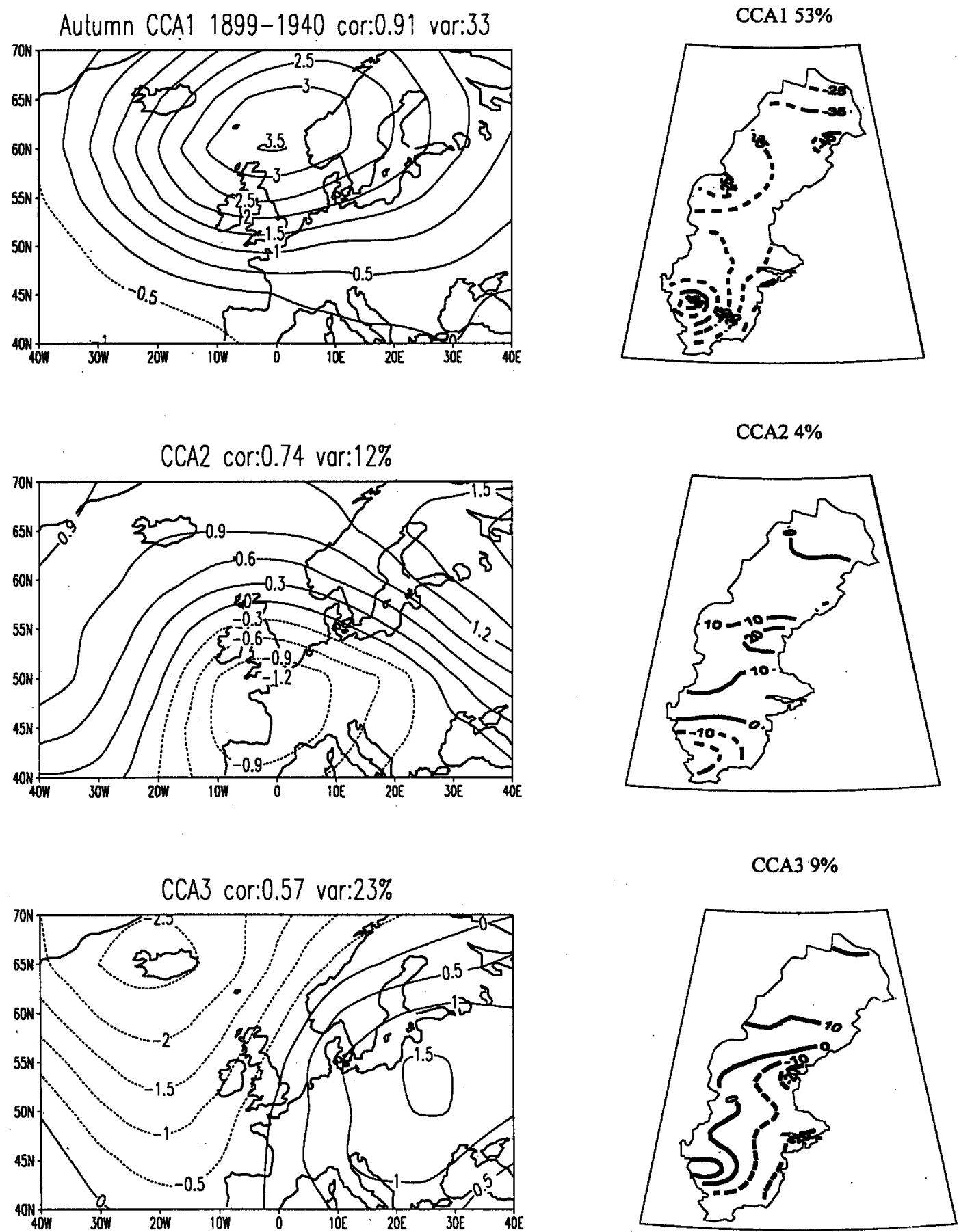

Figure 2. As in Figure 1, but for autumn

winter and autumn pairs, but the North Atlantic SLP pattern is not so deep; the third CCA pair $(r=0.59)$ is similar to the second autumn CCA pair, but with the zero line much more to the north. The second CCA pair $(r=0.65)$ associates the north-south SLP gradient (with two southern secondary centres that induce the Baltic Sea influence) to positive precipitation anomalies in the southeastern and middle part of Sweden. During summer (June, July, August (JJA)), the first CCA pair $(r=0.83)$ links an extended 
cyclonic/anticyclonic SLP structure centred over central Scandinavia, with negative/positive precipitation anomalies in Sweden. The second CCA pair $(r=0.62)$ is quite similar to the second CCA pair in autumn.

The optimal statistical downscaling model was found by using the first six EOFs for SLP and precipitation in the CCA and first six CCA time series in the regression model. Table II shows the skill of the statistical downscaling model (expressed by the fraction of the total variance explained by the reconstructed values through downscaling model, and the correlation coefficient between reconstructed and observed time series) over the independent data set 1899-1940, with the model fitted over the 1941-1990 interval. The linear trend in the original data was removed prior to the statistical downscaling. The model is most skilful for winter and autumn. For spring and summer, the model is skilful only for some stations, but the explained variance is lower. As an example, Figure 3 shows the temporal variation of the observed and reconstructed values for three stations (placed in the southern, southwestern and northern part of Sweden) in autumn.

\subsection{The HadCM2 validation}

3.2.1. Regional precipitation variability. The HadCM2's performance with respect to regional precipitation variability in Sweden was assessed by comparing the main features of the observed and simulated spatial variability given by the most important EOF patterns. The first three EOF patterns best represent these features (Busuioc et al., 1999b). The first EOF pattern shows the same sign of variability over the entire country, with the highest variability in the southwestern part, and the lowest variability in the northern part. The second and third EOF patterns show two to three regions with the same sign of variability, the size of these regions being different from one season to another. Figure 4 presents, as an example, the first three EOF patterns constructed from observations for winter and autumn. These characteristics are stable over time, which is proven by performing EOF analysis over two subintervals. However, the explained variance for the two intervals is different (see Table III). The two subintervals considered are 1899-1940 and 1941-1990. The HadCM2 model reproduces only partially these

Table II. Skill of the statistical downscaling model for the seasonal Swedish precipitation evaluated over the independent data set 1899-1940

\begin{tabular}{|c|c|c|c|c|c|c|c|c|c|c|c|c|c|c|c|c|c|c|}
\hline \multirow[t]{2}{*}{ Season } & & \multicolumn{17}{|c|}{ Stations } \\
\hline & & 1 & 2 & 3 & 4 & 5 & 6 & 7 & 8 & 9 & 10 & 11 & 12 & 13 & 14 & 15 & 16 & 17 \\
\hline \multirow[t]{2}{*}{ Winter } & bbs & 11 & 44 & 44 & 53 & 23 & 32 & 64 & 51 & 50 & 40 & 38 & 1 & 18 & 42 & 26 & 38 & 42 \\
\hline & cor & 49 & 67 & 72 & 75 & 56 & 60 & 82 & 71 & 70 & 63 & 67 & 47 & 43 & 67 & 55 & 61 & 66 \\
\hline \multirow[t]{2}{*}{ Spring } & bbs & 3 & 12 & 10 & 20 & 19 & 16 & 20 & 8 & 17 & 35 & 10 & 6 & 15 & 5 & -6 & 12 & 15 \\
\hline & cor & 33 & 40 & 37 & 47 & 44 & 43 & 50 & 30 & 41 & 59 & 34 & 27 & 39 & 32 & 16 & 36 & 39 \\
\hline \multirow[t]{2}{*}{ Summer } & bbs & 2 & 3 & 22 & 1 & 4 & 30 & 24 & 9 & 16 & 27 & 27 & 5 & 8 & 43 & 23 & 27 & 23 \\
\hline & cor & 16 & 31 & 48 & 23 & 23 & 56 & 49 & 31 & 41 & 52 & 52 & 36 & 31 & 68 & 49 & 52 & 49 \\
\hline \multirow[t]{3}{*}{ Autumn } & bbs & 31 & 55 & 51 & 15 & 6 & 60 & 65 & 10 & 16 & 60 & 17 & 18 & 25 & 49 & 54 & 42 & 36 \\
\hline & cor & 57 & 74 & 72 & 47 & 34 & 78 & 81 & 43 & 46 & 77 & 52 & 47 & 60 & 70 & 74 & 64 & 60 \\
\hline & & 18 & 19 & 20 & 21 & 22 & 23 & 24 & 25 & 26 & 27 & 28 & 29 & 30 & 31 & 32 & 33 & Average \\
\hline \multirow[t]{2}{*}{ Winter } & bbs & 3 & 37 & 17 & 32 & 32 & 29 & 24 & 26 & 15 & 23 & 44 & 25 & 19 & 24 & 40 & -8 & 67 \\
\hline & cor & 31 & 62 & 46 & 57 & 57 & 55 & 49 & 53 & 39 & 49 & 68 & 50 & 45 & 52 & 64 & 13 & 87 \\
\hline \multirow[t]{2}{*}{ Spring } & bbs & 5 & 13 & -4 & 6 & 0 & 5 & 3 & 6 & 20 & 23 & -2 & -9 & 38 & -13 & 5 & -10 & 35 \\
\hline & cor & 28 & 39 & 19 & 27 & 22 & 30 & 24 & 28 & 46 & 48 & 21 & 23 & 62 & 17 & 28 & 17 & 60 \\
\hline \multirow[t]{2}{*}{ Summer } & bbs & 14 & 19 & 16 & 4 & 21 & 15 & -2 & 1 & 21 & 7 & 18 & 6 & 1 & 23 & 19 & -8 & 41 \\
\hline & cor & 40 & 43 & 41 & 32 & 46 & 41 & 30 & 35 & 47 & 36 & 431 & 35 & 26 & 49 & 46 & 17 & 65 \\
\hline \multirow[t]{2}{*}{ Autumn } & bbs & 18 & 65 & 60 & 37 & 41 & 26 & 13 & 21 & 21 & 20 & 30 & 35 & 50 & 44 & 36 & 43 & 69 \\
\hline & cor & 57 & 81 & 78 & 63 & 65 & 53 & 36 & 46 & 50 & 45 & 58 & 60 & 72 & 67 & 61 & 67 & 83 \\
\hline
\end{tabular}

The model is fitted over the 1941-1990 interval. The skill (bbs) is expressed by the fraction of the total variance explained by the reconstructed values through downscaling model and correlation coefficient between reconstructed and observed time series (cor). The respective results are presented for every station, as well as for the spatial average over all stations. 


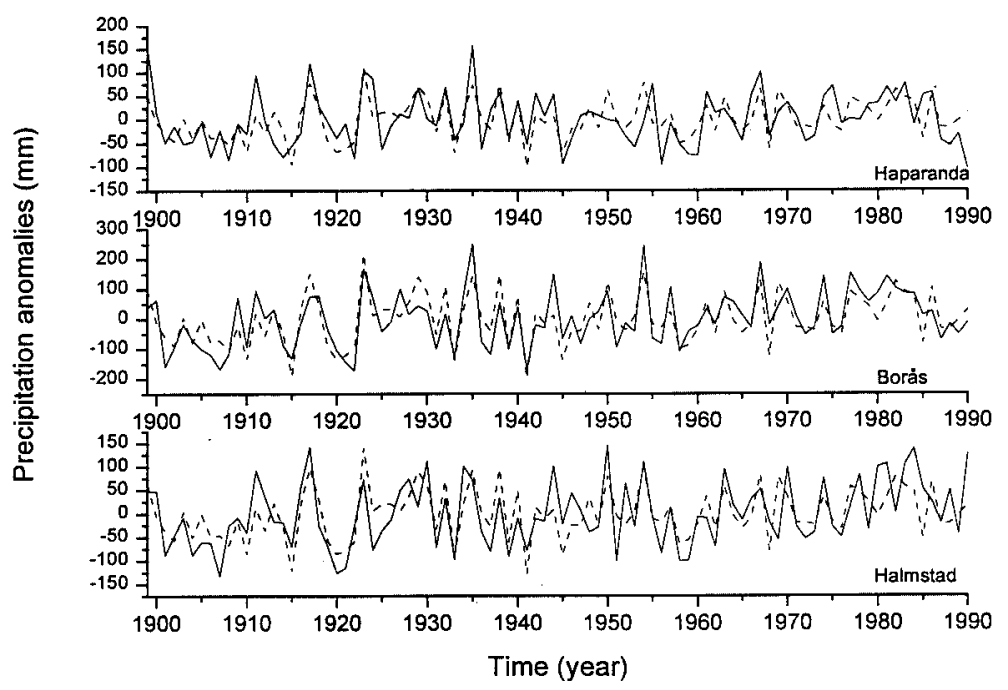

Figure 3. Autumn precipitation anomalies for 1899-1990 at three stations as derived from local station measurements (solid line) and as derived indirectly from the observed large-scale SLP anomalies by using the downscaling model (dashed line) built over 1899-1940 interval

characteristics. Some disagreements between spatial patterns and explained variance are revealed. Figure 5 shows the first three EOF patterns, as derived from GCM grid point data (control run). The GCM overestimates explained variance of the first EOF (summer), second EOF (spring, summer and autumn) and third EOF (autumn). In autumn, the explained variance of the first EOF is underestimated by the GCM. The comparison is made with the 1899-1940 interval. As changes in the observed explained variance can be seen for the two subintervals, it could be concluded that this characteristic is induced by the natural climate variability. Another reason could be that the coarse resolution over which the GCM is integrated and the short time series of simulations.

3.2.2. SLP variability. The patterns of the first three SLP EOFs represent the main modes of atmospheric circulation variability over the North Atlantic-European region. These modes explain more than $80 \%$ of the total variance for winter and autumn, and about $70 \%$ for summer (see Table III). Except for spring and summer, the order of these patterns changes over the two subintervals (1899-1940, 1941-1990) owing to differences in the explained variance. This result reveals an enhancement/diminution of some atmospheric circulation mechanisms over the analysed time interval that could affect the precipitation regime in Sweden. The principal mode of SLP variability (given by the first EOF pattern) is represented by the NAO, except for summer. The second and third EOF patterns are represented by a dipole structure, generally, with reversed sign between continental Europe and the North Atlantic Ocean, and a cyclonic/anticyclonic structure centred over the British Isles (centre moves from one season to another). The order of these patterns changes for some seasons. Figures 6 and 7 present the observed first three EOF patterns for the two subintervals in winter and autumn, respectively.

The HadCM2 model adequately reproduces the first three SLP EOF patterns for all seasons, except summer, when only the first EOF is adequately reproduced. Figure 8 presents the first three EOF patterns derived from the GCM simulation (control run) for winter and autumn. The explained variance of the first EOF is overestimated for spring and summer (see Table III). This means an overestimation of some circulation types, which could indicate a failure in simulation of regional precipitation. On the other hand, the differences between the observed explained variance of the two subintervals presented above, which could be induced by natural climate variability, or something else could be an obstacle for GCM validation. Hulme (1994) shows the importance of the observed reference period for model validation. The uncertainty about the true observed SLP hinders the task of model validation. 


\section{WINTER}

EOF1 $47 \%$
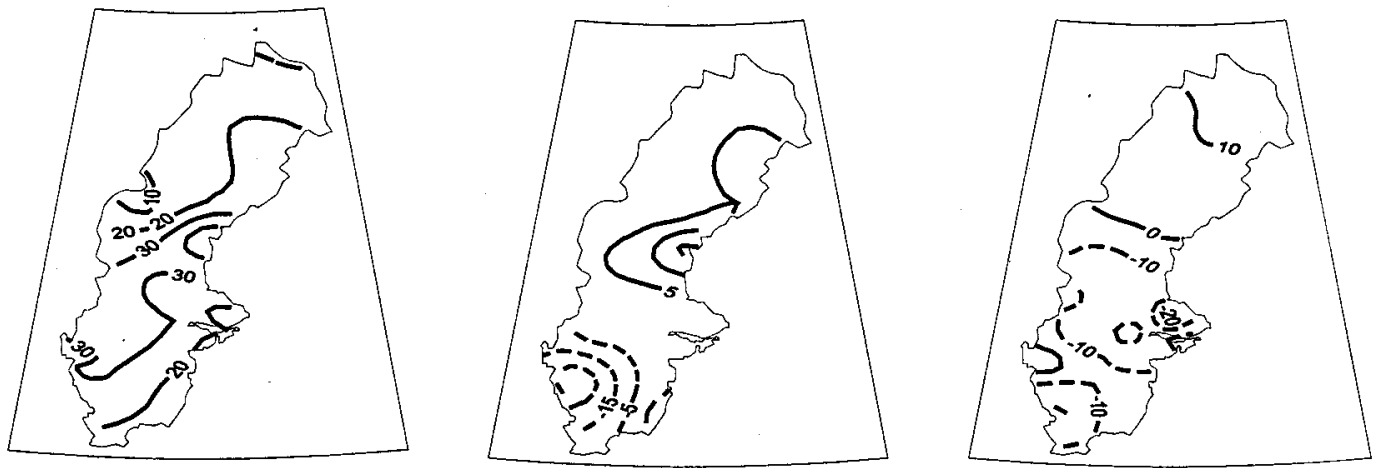

AUTUMN

EOF1 $57 \%$

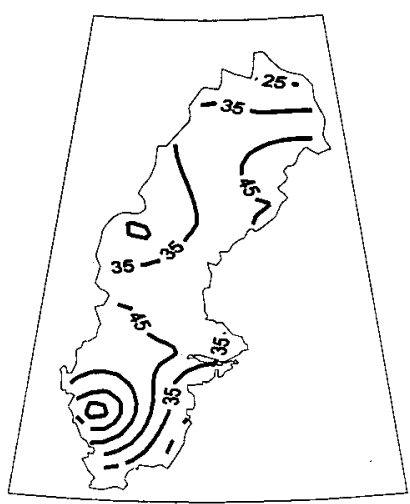

EOF2 $12 \%$
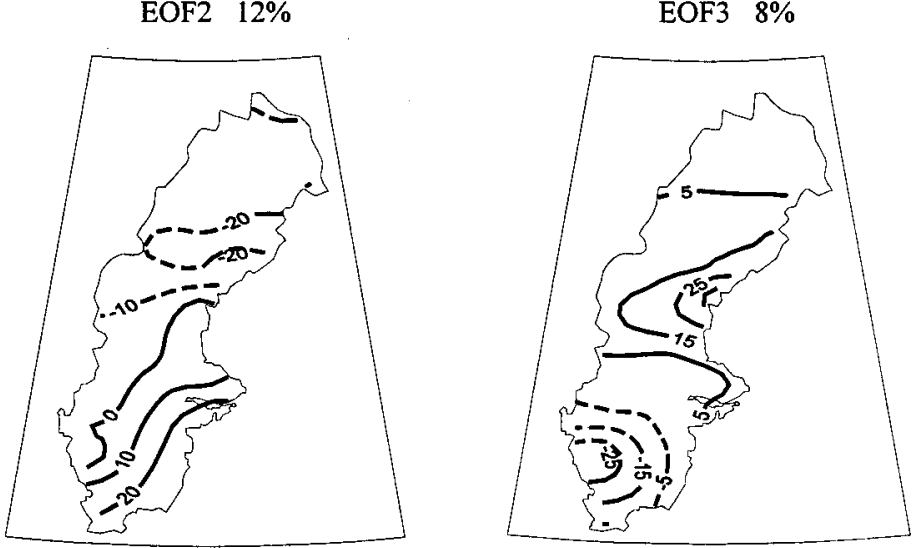

Figure 4. The patterns of the first three EOFs of Swedish precipitation as derived from the observed seasonal amounts (1899-1940) for winter and autumn

Table III. Explained variance of the first three EOF patterns of the monthly mean SLP and monthly total amount of Swedish precipitation

\begin{tabular}{|c|c|c|c|c|c|c|c|c|c|c|}
\hline \multirow[t]{3}{*}{ Season } & & \multicolumn{6}{|c|}{ Observed } & \multirow{2}{*}{\multicolumn{3}{|c|}{$\begin{array}{l}\text { GCM } \\
\text { Control run }\end{array}$}} \\
\hline & & \multicolumn{3}{|c|}{ 1899-1940 } & \multicolumn{3}{|c|}{ 1941-1990 } & & & \\
\hline & & EOF1 & EOF2 & EOF3 & EOF1 & EOF2 & EOF3 & EOF1 & EOF2 & EOF3 \\
\hline \multirow[t]{2}{*}{ Winter } & SLP & 35 & 33 & 13 & 48 & 20 & 16 & 44 & 33 & 10 \\
\hline & Precipitation & 47 & 12 & 10 & 59 & 14 & 17 & 50 & 19 & 13 \\
\hline \multirow[t]{2}{*}{ Spring } & SLP & 41 & 23 & 14 & 35 & 25 & 17 & 54 & 19 & 15 \\
\hline & Precipitation & 43 & 14 & 9 & 56 & 10 & 6 & 47 & 25 & 11 \\
\hline \multirow[t]{2}{*}{ Summer } & SLP & 33 & 24 & 17 & 35 & 25 & 18 & 58 & 17 & 12 \\
\hline & Precipitation & 37 & 14 & 7 & 49 & 9 & 5 & 56 & 21 & 7 \\
\hline \multirow[t]{2}{*}{ Autumn } & SLP & 45 & 27 & 9 & 32 & 30 & 16 & 47 & 23 & 16 \\
\hline & Precipitation & 57 & 12 & 8 & 55 & 11 & 7 & 47 & 24 & 15 \\
\hline
\end{tabular}




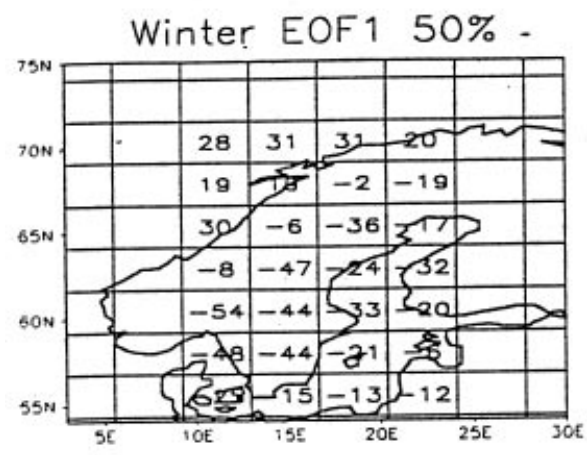

EOF $219 \%$

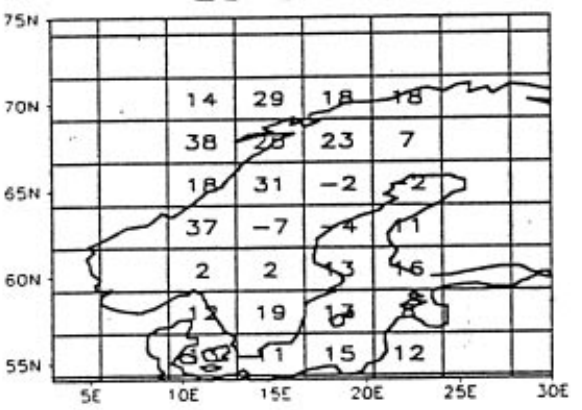

EOF3 $13 \%$

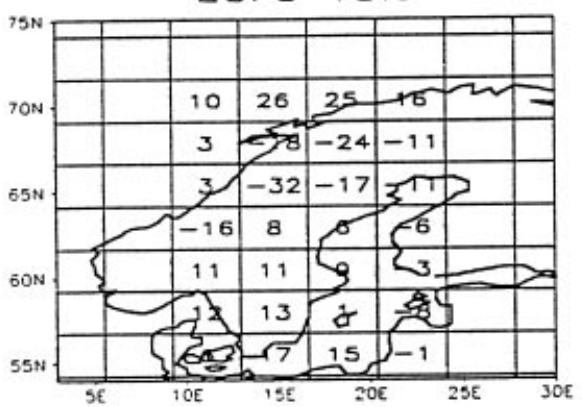

Autumn EOF $1.47 \%$

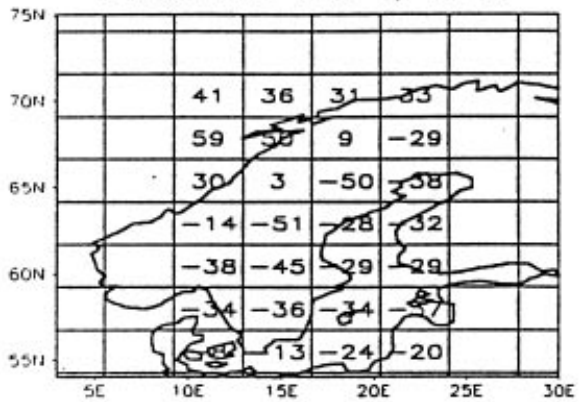

EOF2 $24 \%$

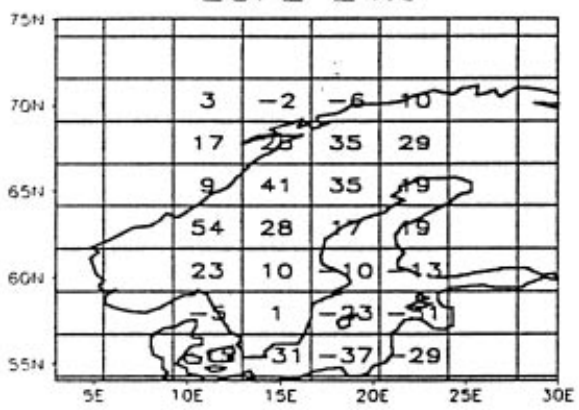

EOF3 $15 \%$

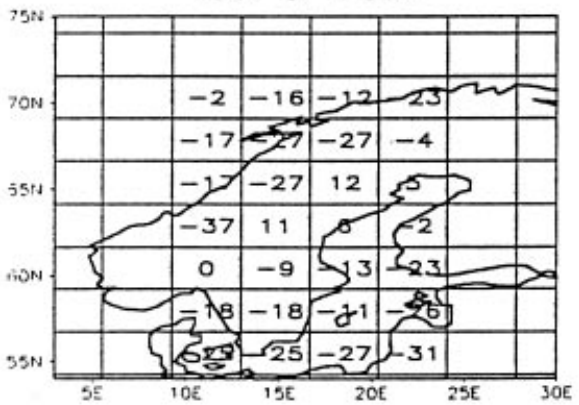

Figure 5. The patterns of the first three EOFs of Swedish precipitation as derived from the HadCM2 simulation (control run) for winter and autumn

3.2.3. Links between SLP and Swedish precipitation. The patterns of the first three CCA pairs derived from the GCM grid point data (control run) are only partially similar to those derived from observation, even if they show physically reasonable mechanisms. The link is strong for all seasons, but the order of the SLP patterns is sometimes reversed, or the centre of the spatial structure has moved. The model overestimates the explained variance for some patterns (Table IV). This is the reason why only the first three EOFs of SLP and precipitation from the GCM were used in CCA analysis. In addition, other combinations of the number of EOFs in the CCA for the observed data set (different from the optimal combination in the statistical downscaling model presented in Section 3.1) sometimes give more similar CCA patterns, as compared with those derived from the GCM data. For example, in winter, using the first three EOFs for SLP and precipitation, the resemblance to the GCM CCA patterns is much better; in fact, these EOF patterns explain more than $80 \%$ of the total variance. These results reveal that the 

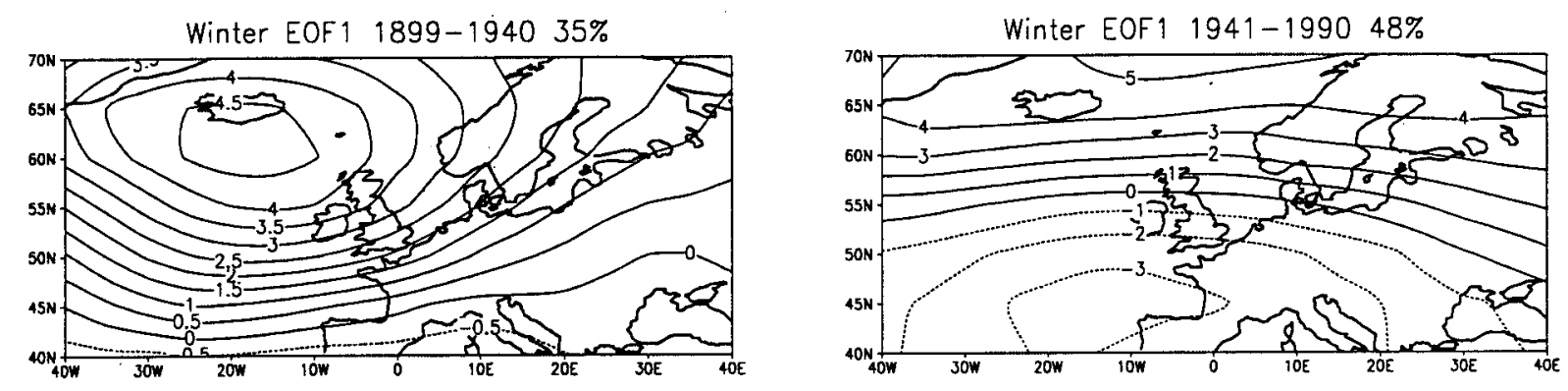

EOF2 $33 \%$

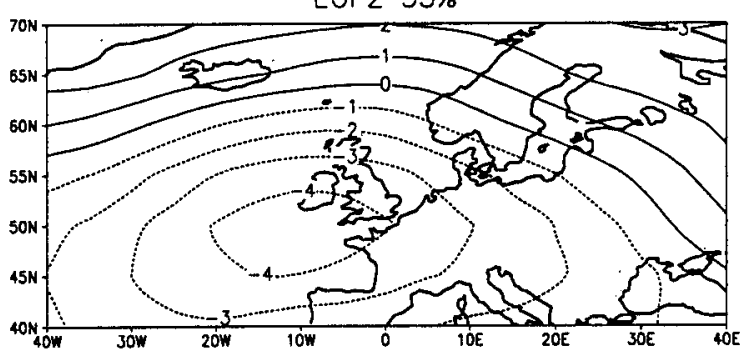

EOF3 $13 \%$

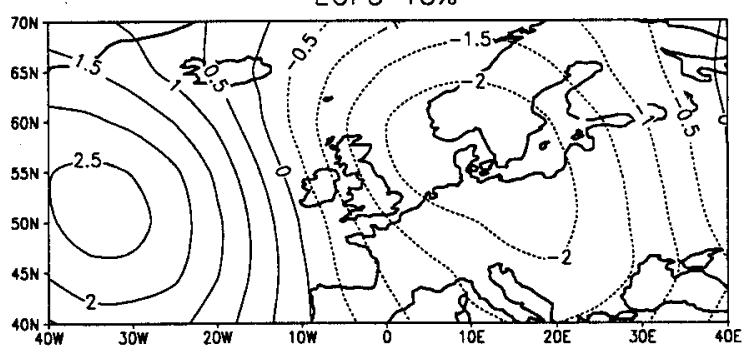

EOF2 $20 \%$

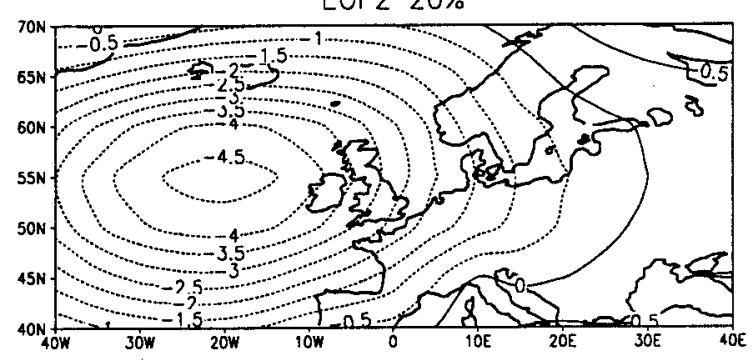

EOF3 $16 \%$

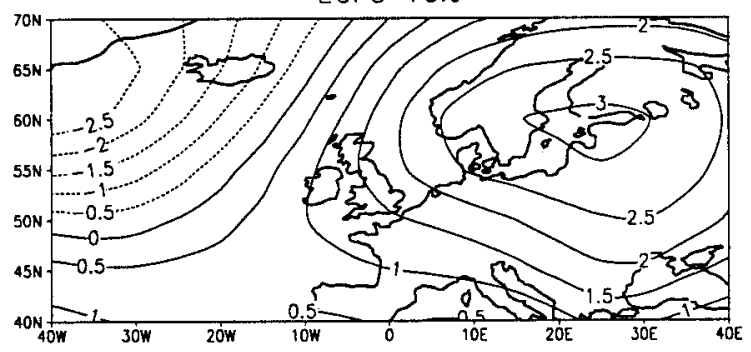

Figure 6. The patterns of the first three EOFs of winter SLP as derived from the observed seasonal mean for the two subintervals. The fraction of the respective total variance explained by each EOF is given in the upper right of each panel

HadCM2 GCM is not able to reproduce the complexity of all circulation mechanisms controlling regional precipitation variability in Sweden, but the most important ones (given by the first CCA pair) are quite well reproduced in winter and autumn. Some mechanisms are overestimated or underestimated, which may lead to failure in precipitation simulation.

Figures 9 and 10 show, as an example, the first three CCA patterns, as derived from the GCM grid points for winter and autumn. These patterns are compared to those presented in Figures 1 and 2, respectively. During winter, the NAO pattern (given by the first CCA pair) is fairly well reproduced, but the line separating the negative and positive SLP anomalies is placed to the north in GCM simulation. The CCA patterns of precipitation are similar to observed ones. The SLP pattern of the second CCA pair is closer to the SLP pattern of the observed third CCA pair, with larger negative anomalies and centres moved to the north. This pattern is associated with positive Swedish precipitation anomalies over the entire country (plausible mechanism from physical point of view), which is dissimilar to the observed one. The observed negative SLP anomalies (because of the position of their centres) affect only precipitation in the southern half of Sweden. The variance explained by the patterns of the second CCA pair derived from GCM simulation is overestimated.

For autumn, the NAO pattern, reproduced in the GCM simulation by the SLP pattern of the third CCA pair (against the first CCA pair in observation) is underestimated. The SLP pattern of the second 

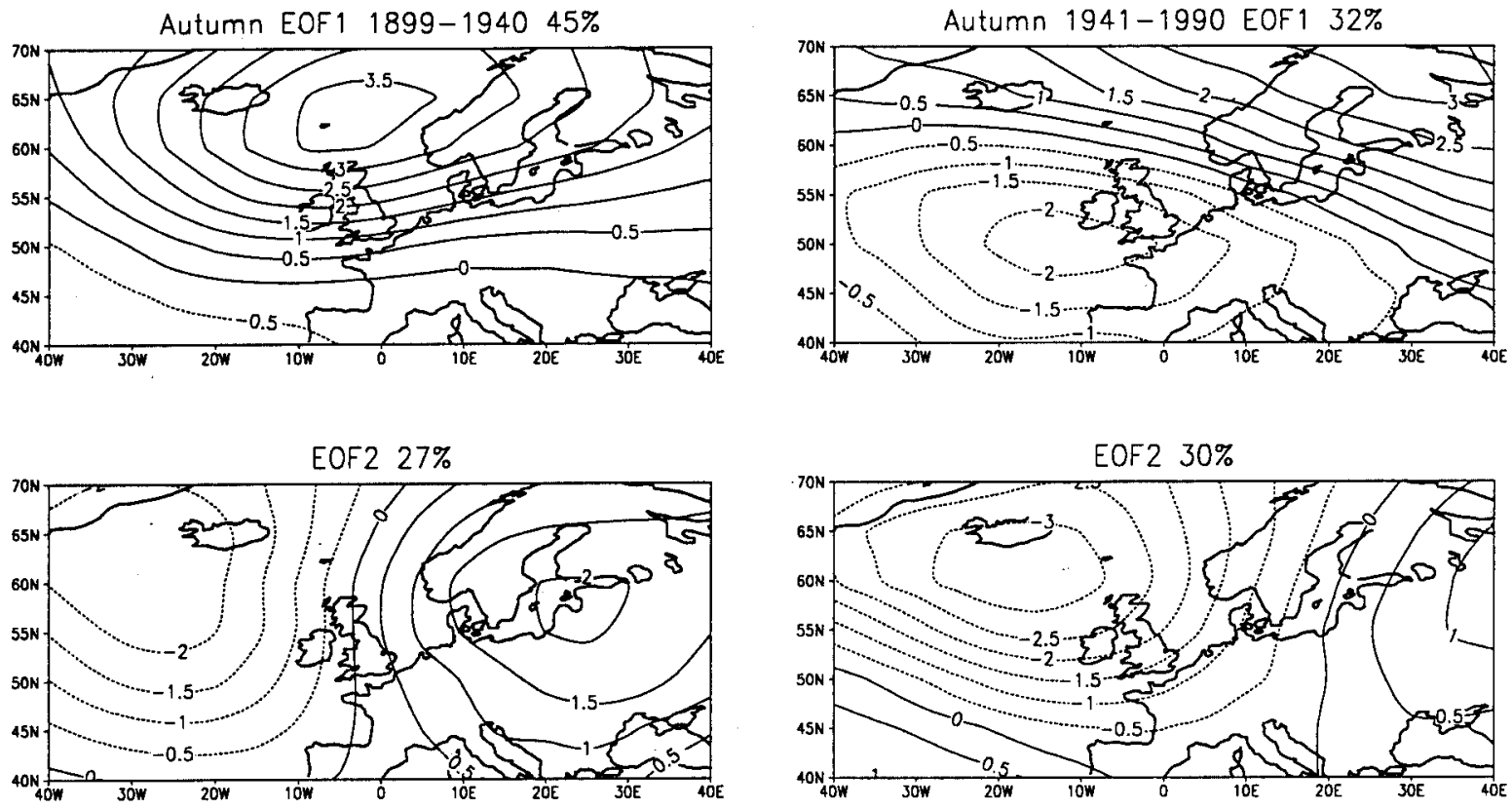

EOF $39 \%$
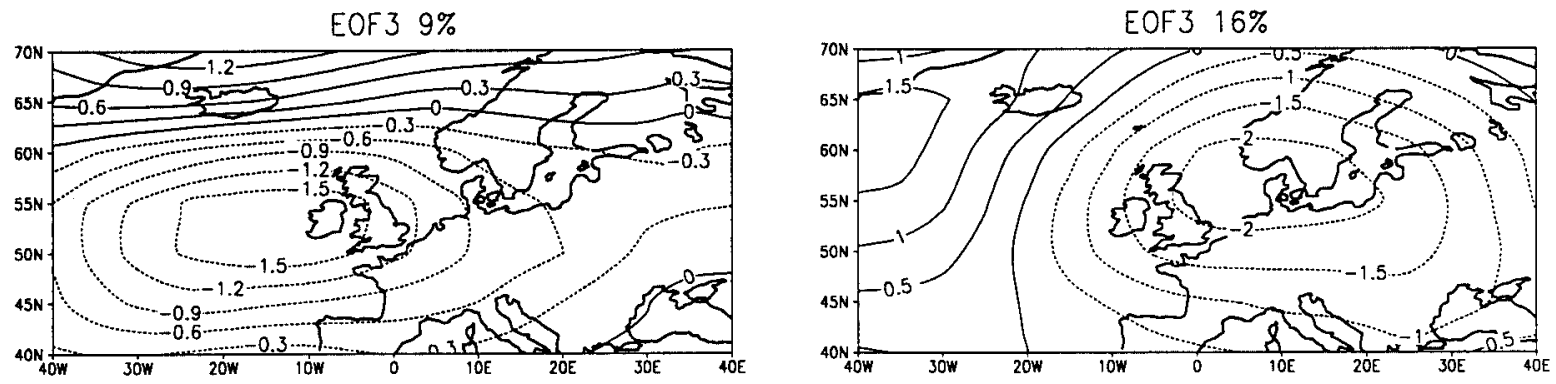

Figure 7. As in Figure 5, but for autumn

CCA pair is quite well simulated, while the SLP pattern of the first GCM CCA pair is similar to the third observed CCA pair. The short length of the GCM time series could be one reason for these failures, as could the choice of observed period for comparison. The corresponding CCA patterns of precipitation are quite similar to observed ones, showing a similar physical link, in spite of the coarse resolution of the GCM.

\subsection{Climate change scenarios}

The climate changes under the increased $\mathrm{CO}_{2}$ concentrations derived from the statistical downscaling model are compared with those derived directly from the GCM grid points, and a procedure to assess the validity of the downscaling model for changed climate conditions is used. More details about this procedure are presented by Busuioc et al. (1999a), and also mentioned in Section 2. The grid point climate signal shows an increase in seasonal precipitation in Sweden for all seasons, except for spring (no significant changes), and in the southern part in winter (Figure 11). By using the optimal statistical models presented above, the two signals are similar only for summer (Figure 12). For autumn, the downscaled signal shows an increase of precipitation only for the south-western and northern parts (Figure 13). The same signal is obtained with the model fitted for both the subintervals. By using fewer CCA time series in the regression model, it is noted that the result is stable, except for the case when only the first CCA 

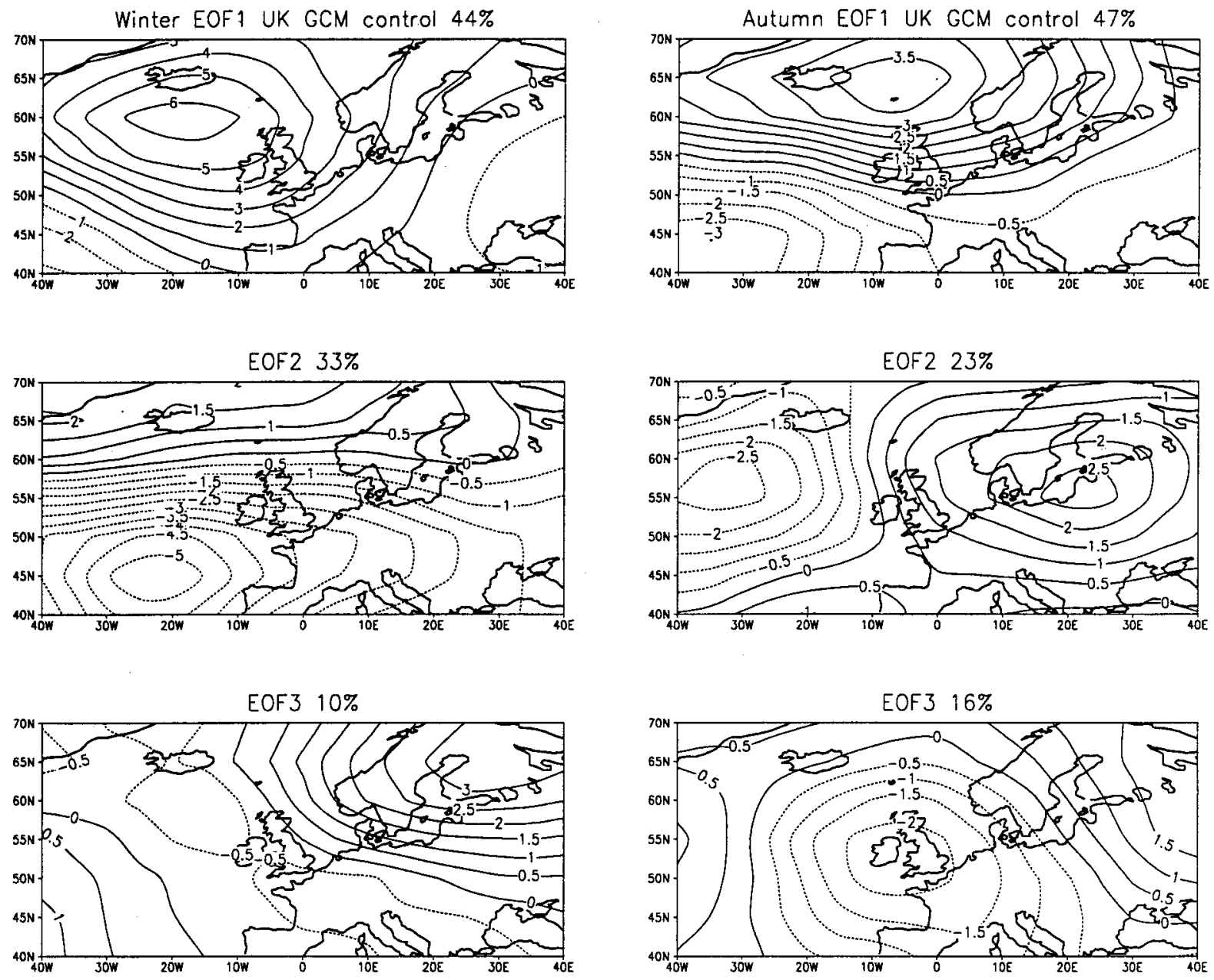

Figure 8. As in Figure 6, but for winter and autumn, as derived from the HadCM2 simulation (control run)

time series is used for the model fitted over the 1899-1940 interval (Figure 13). In this case, a climate change signal more similar to that of the GCM (e.g. increasing precipitation over the entire country) is obtained, but exceeding the downscaled precipitation is smaller.

To clarify what version of the statistical model is more appropriate, the degree to which the statistical model reproduces the observed trend was verified. Figure 15 presents the verification for two versions of the model, one using the first two CCA time series in regression model, and the other using only the first CCA time series. It was found that the last version is the best. Considering the fact that the skill of this model's version is close enough to the other one (not shown), this additional performance (e.g. to reproduce the observed trend) suggests that this model is optimal for climate change applications. In addition, in this case, the downscaled climate signal is similar to those obtained directly from GCM grid points. According to the comments presented in Section 2 about the validity of the downscaling results and performance of GCM in modelling regional precipitation and processes determining the link between precipitation and large-scale circulation, we are more confident of this downscaled signal.

For winter, a similar verification has been made: by using the optimal downscaling model, a decrease in precipitation for all Swedish stations (more significant in the south) was found (Figure 14); by using only the first CCA time series (Figure 14), a slight increase (except for the southeastern part) in precipitation was found. In the latter case, the climate change signal is similar to the GCM-simulated one, but the amplitude is different for the northern and northwestern parts. The same result is obtained if the first three EOFs are used in CCA and the first two CCA time series are retained in the regression model. 


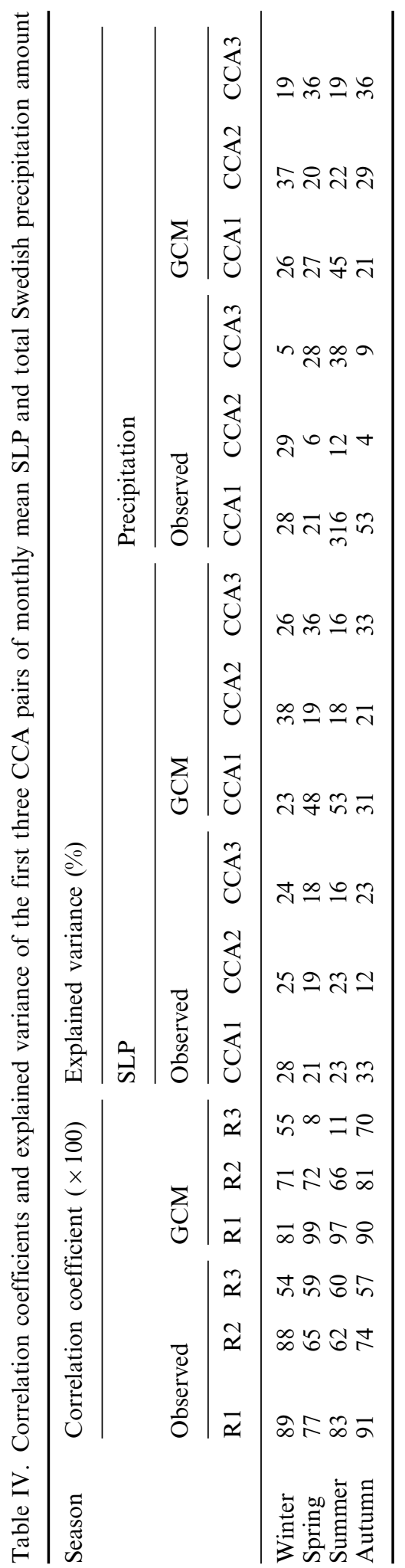


Winter CCA1 UK GCM cor:0.81 23\%

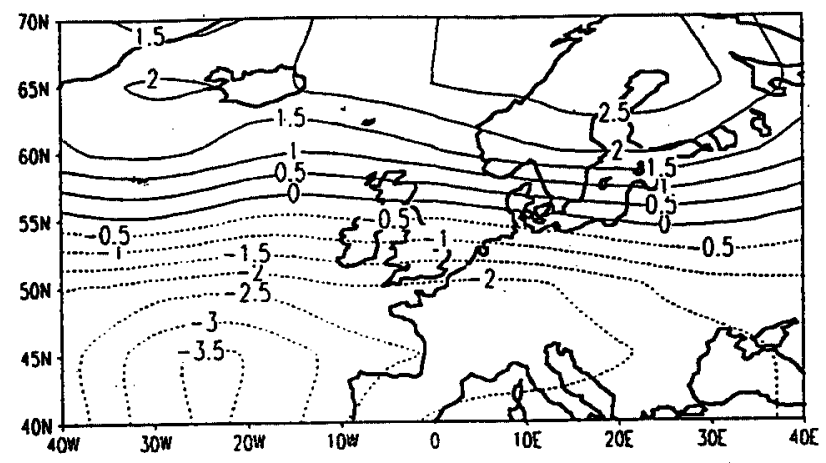

CCA2 cor: $0.7138 \%$

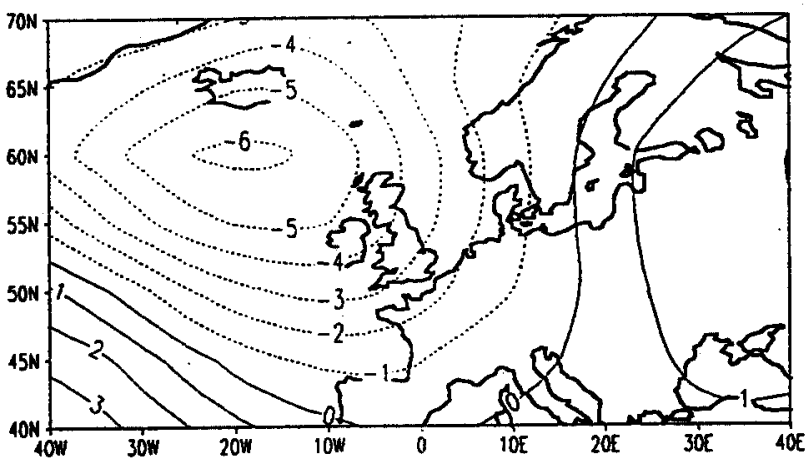

CCA3 cor: $0.5526 \%$

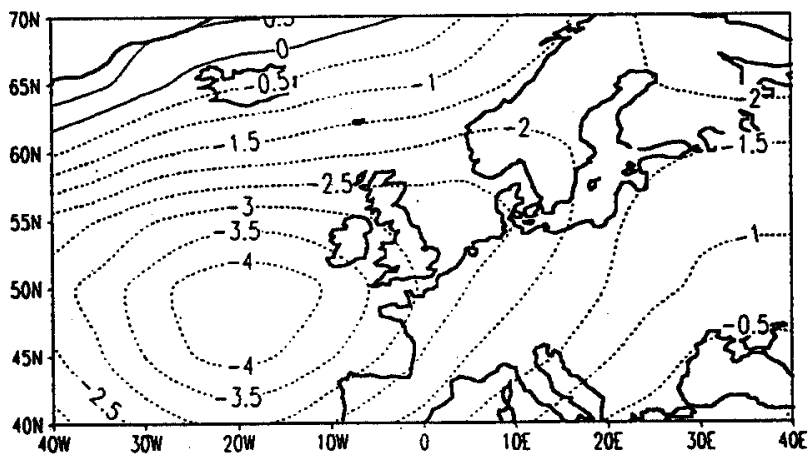

Winter CCA1 26\%

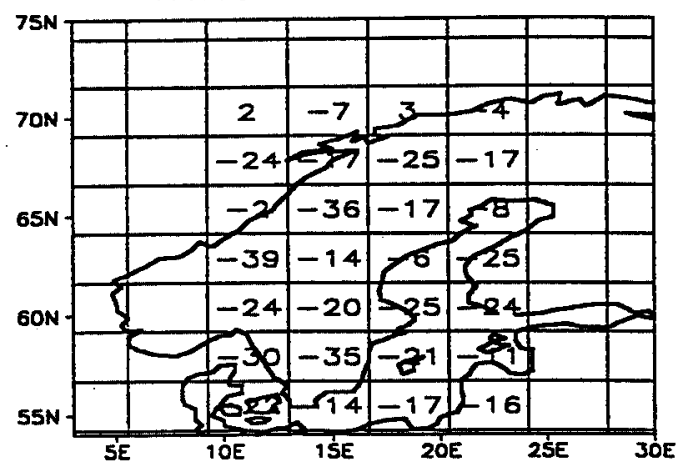

CCA2 37\%

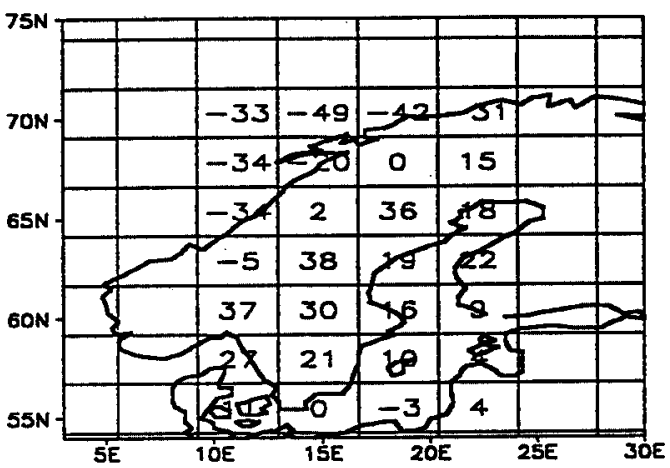

CCA3 $19 \%$

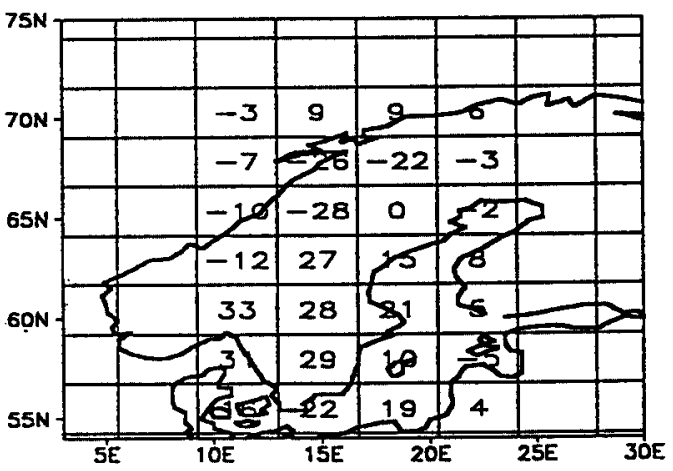

Figure 9. The patterns of the first three CCA pairs of winter mean SLP and winter total precipitation over Sweden as derived from the HadCM2 grid points (control run)

\section{CONCLUDING REMARKS}

The link between seasonal Swedish precipitation and large-scale SLP variability is strong in all seasons, especially for winter and autumn. For these two seasons, the link is mainly a consequence of the NAO pattern. In winter, another equally important atmospheric circulation mechanism is related to a cyclonic/anticyclonic structure centred over southern Scandinavia. By considering two independent 
Autumn CCA1 UK GCM $0.9031 \%$

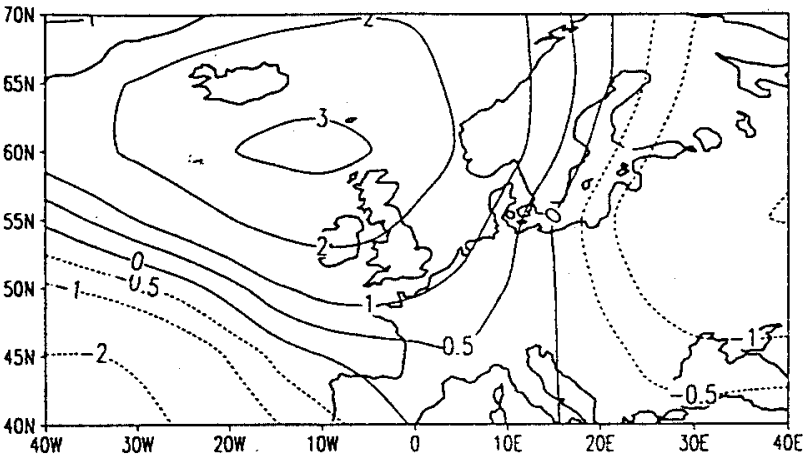

CCA2 $0.8121 \%$

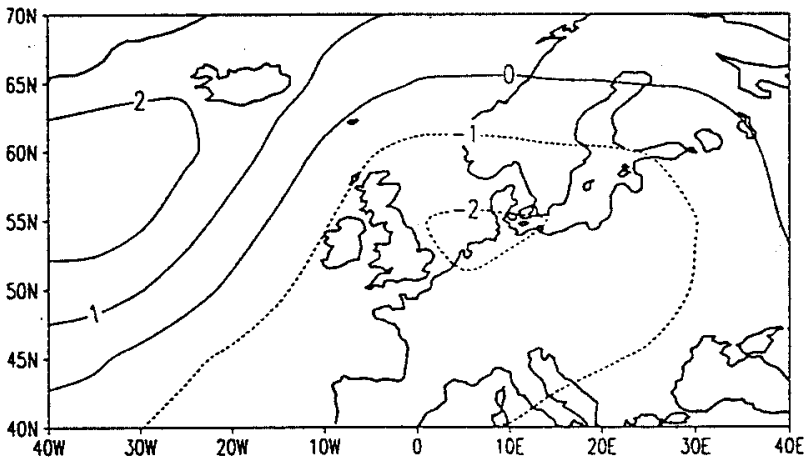

CCA3 $0.7033 \%$

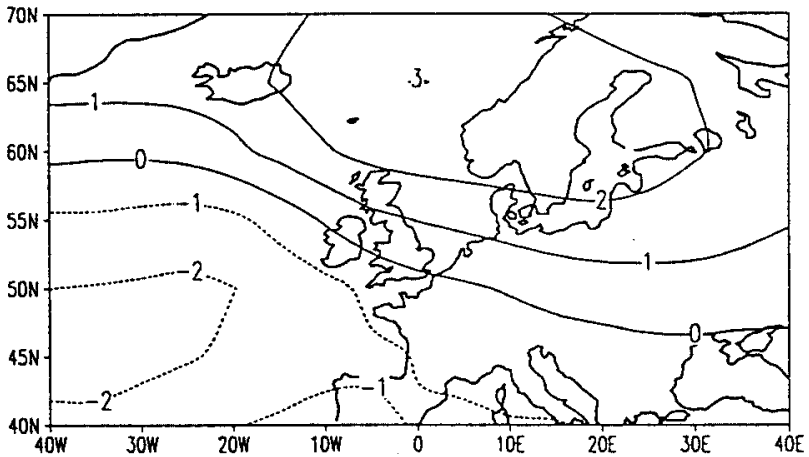

Autumn CCA1 $21 \%$

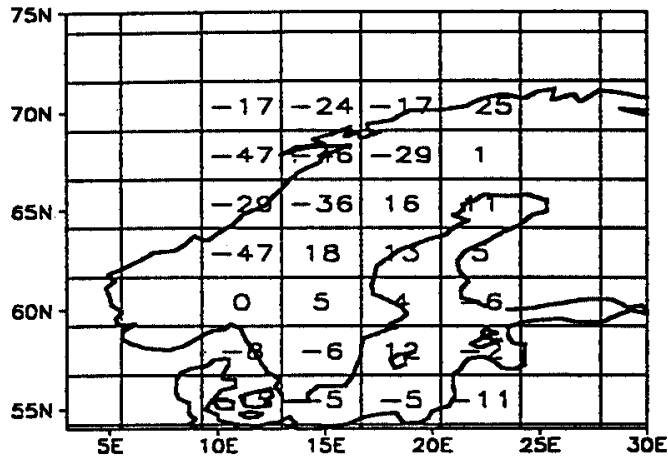

CCA2 29\%

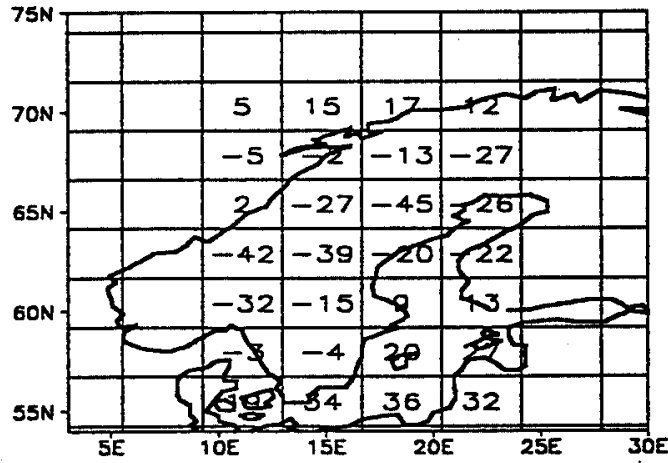

CCA3 $36 \%$

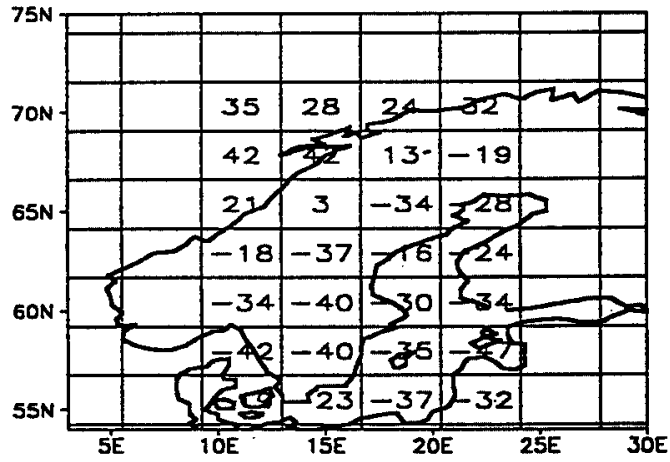

Figure 10. As in Figure 9, but for autumn

intervals, 1899-1940 and 1941-1990, of the observational period, it was found that, in the past century, this connection has remained approximately unchanged in time for all seasons except spring. Defining the skill of the statistical downscaling model in terms of the verification for the sub-interval independent from the fitting interval, the downscaling model built on the basis of this link is skilful for all seasons, especially for winter and autumn. The statistical model is able to reproduce adequately the low frequency variability of the observed time series (linear trend, changes in the mean), but this performance differs from one station to another. 
Winter

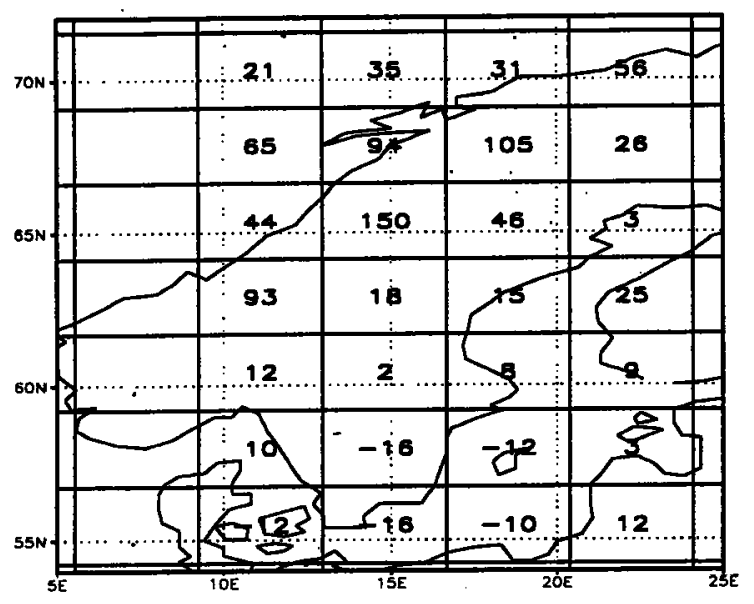

Summer

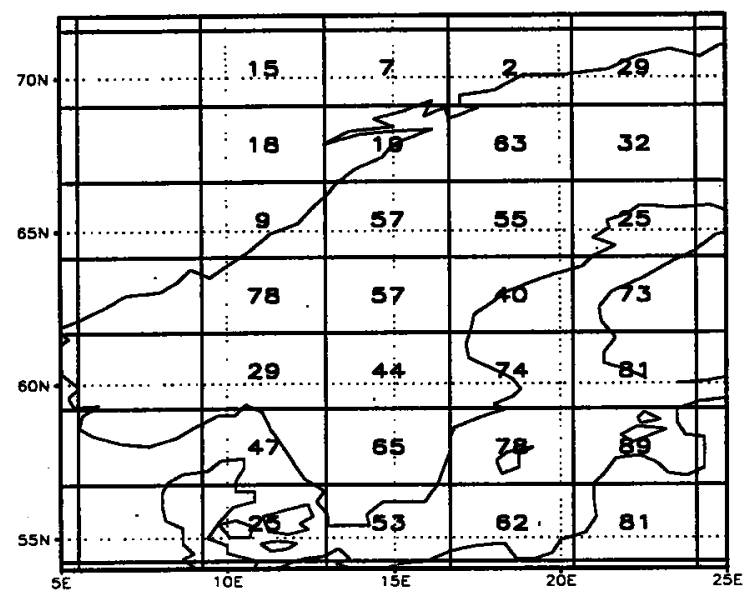

Spring

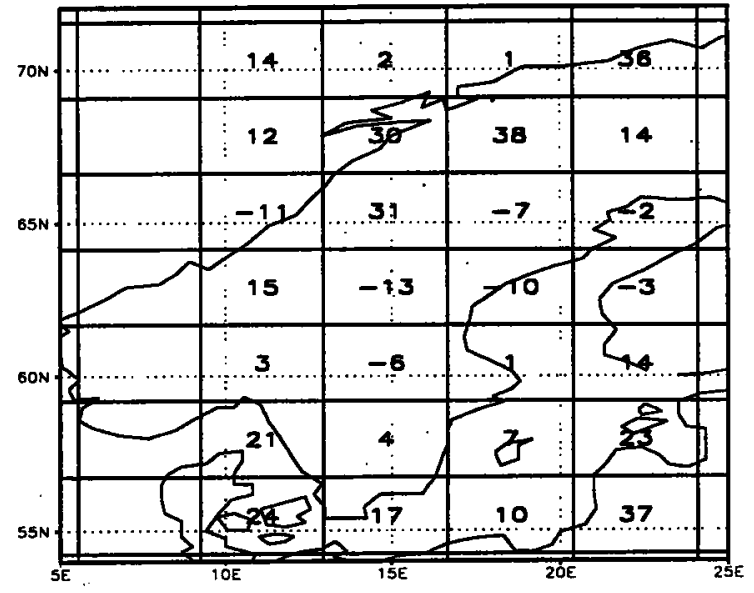

Autumn

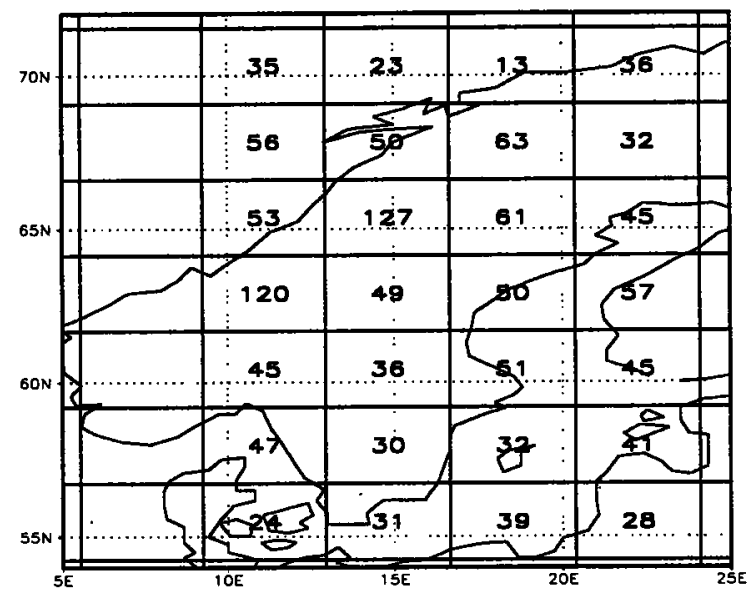

Figure 11. Changes of seasonal precipitation in Sweden $\left(\mathrm{mm} /\right.$ season) owing to $\mathrm{CO}_{2}$ concentration increase $\left(2.5 \times \mathrm{CO}_{2}\right.$ experiment), as derived from the HadCM2 time-slice experiments. The changes are derived directly from the grid point precipitation of the GCM as differences between the means from the $2.5 \times \mathrm{CO}_{2}$ and the $1 \times \mathrm{CO}_{2}$ experiments

The observed link is only partially reproduced by the HadCM2 model (best reproduced in winter and autumn), while the large-scale SLP variability is fairly well reproduced in all seasons. However, this relationship does not reproduce all the complexities of the actual observed link. This result could be explained by the overestimation/underestimation of the main modes of SLP variability in the GCM simulations that induce another hierarchy of the atmospheric circulation mechanisms controlling the regional precipitation variability compared to reality. Another reason could be the failure of the GCM in simulating the regional scale processes dependent on sub-grid scale physics, which are empirically parameterized.

An important conclusion of this work is that, for climate change purposes, the optimal statistical downscaling model should be selected with regard to its ability to capture the climate change signal. By choosing fewer CCA pairs to build the model, the skill of the model in reproducing the interannual variability is reduced. At the same time, the low frequency variability (e.g. general trend) is better represented, which is most desirable. 

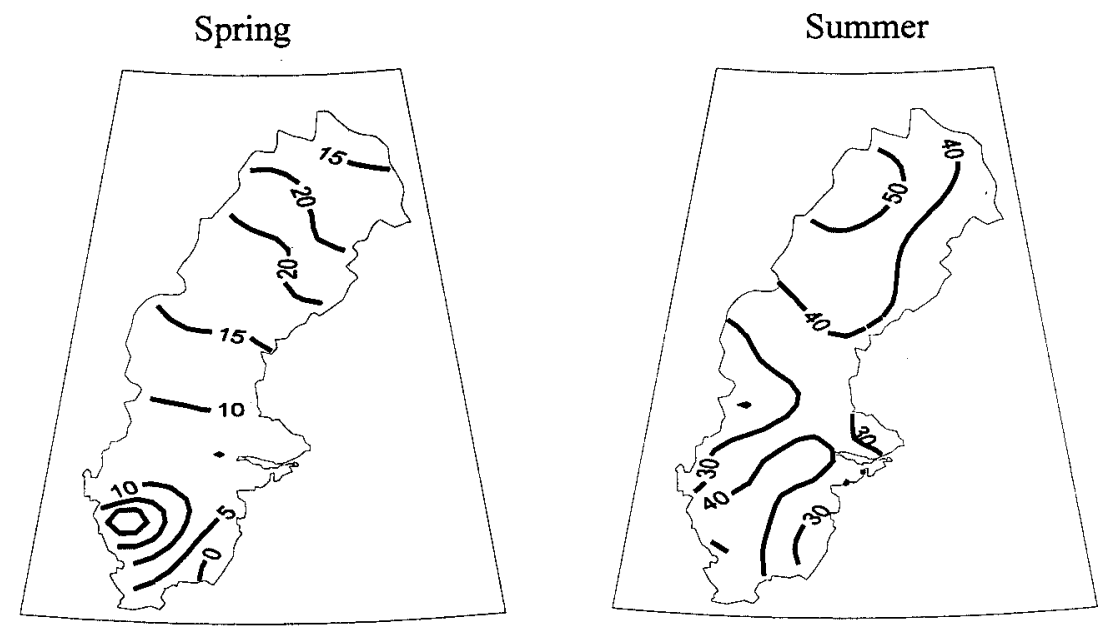

Figure 12. Changes of spring and summer precipitation in Sweden $\left(\mathrm{mm} /\right.$ season) owing to $\mathrm{CO}_{2}$ concentration increase $\left(2.5 \times \mathrm{CO}_{2}\right.$ experiment), as derived indirectly from the GCM-simulated large-scale SLP anomalies $\left(2.5 \times \mathrm{CO}_{2}-1 \times \mathrm{CO}_{2}\right)$ through optimum statistical downscaling models

\section{Autumn}

6 EOFs, 6 CCA

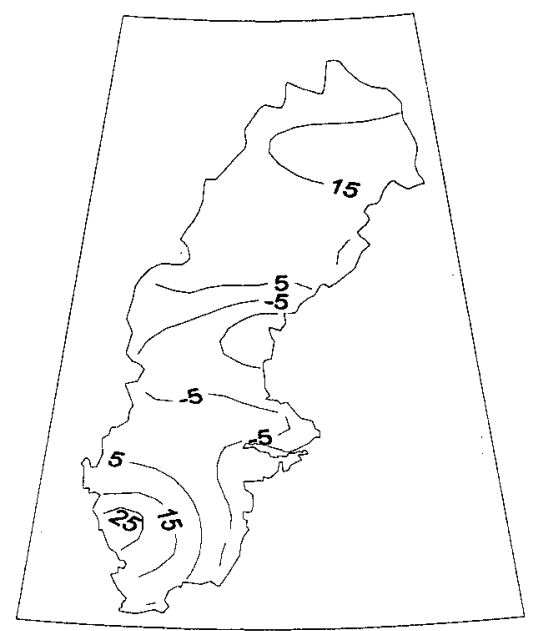

6 EOFs, 1 CCA

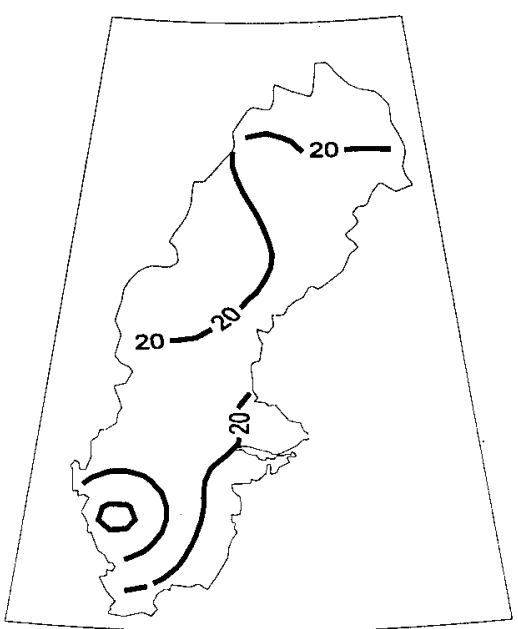

Figure 13. Changes of autumn precipitation in Sweden (mm/season) owing to $\mathrm{CO}_{2}$ concentration increase $\left(2.5 \times \mathrm{CO}_{2}\right.$ experiment) as derived indirectly from the GCM-simulated large-scale SLP anomalies through optimum statistical downscaling model (six retained CCA time series) and through downscaling model built by using only first CCA time series

The climate change signal derived directly from the GCM grid point data under $2.5 \times \mathrm{CO}_{2}$ scenario is similar to those obtained indirectly through the statistical downscaling model (selected by the rule presented above), especially for summer and autumn (increase of precipitation amount), with a dissimilarity of amplitude of change in autumn. Even if the two signals are similar in winter (increase of precipitation except for southern Sweden), the amplitudes of change are very different in northern Sweden. In spring, the two signals are similar, except for middle Sweden. As GCM is reliable in modelling the link between precipitation and large-scale circulation for winter and autumn, and considering the arguments presented in Section 2, we are more confident in the validity of the relationship given by the 


\section{Winter}

$6 \mathrm{EOFs}, 6 \mathrm{CCA}$

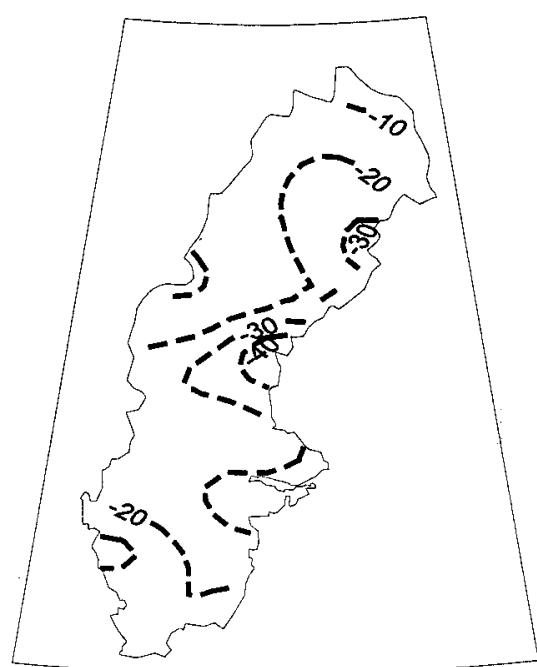

6 EOFs, 1 CCA

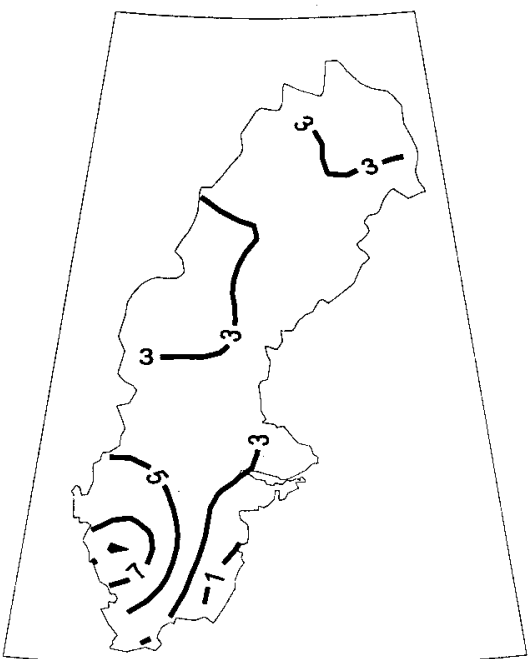

Figure 14. As in Figure 13, but for winter

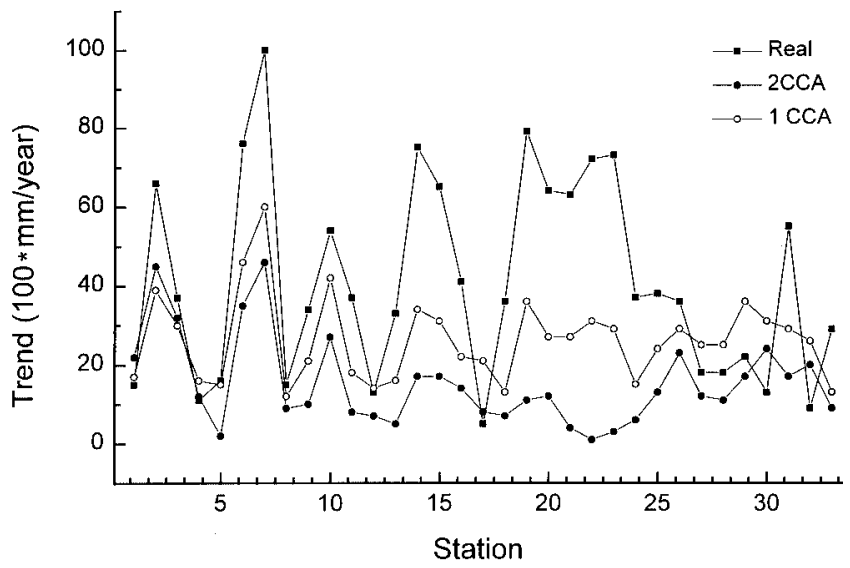

Figure 15. Trend of the autumn Swedish precipitation over $1899-1990$ period (mm/year $* 100)$, as derived from observation and from reconstructed values. For reconstruction, the statistical downscaling model built retaining the first two CCA time series, and only first CCA time series is used, respectively

CCA model in the changed future climate for these seasons. It should be noted that this result is not an incontestable proof; it only shows an increased confidence. Therefore, owing to the increase of $\mathrm{CO}_{2}$ concentration, precipitation in Sweden will increase in autumn over the entire country, and in the northern part in winter (when an uncertainty about the amplitude of this change could be noted). For the other seasons, no conclusion can be drawn about the validity of either model, as the GCM is not reliable in reproducing the observed link between precipitation and SLP or the two climate signals are different.

Application of this procedure to more GCMs could lead to a more reliable measure of uncertainty upon the estimation of regional climate change in a perturbed climate. 


\section{ACKNOWLEDGEMENTS}

This work has been achieved through SWECLIM Programme supported by MISTRA and SMHI. The authors thank Hans Alexandersson for providing the NACD data and useful discussion. Jubileumsfonden from the Göteborg University supported Aristita Busuioc's visit to the Department of Earth Sciences. Youmin Chen is acknowledged for assistance of some plotting. This research is also partly supported by two NFR grants (G-AA/GU 11739-300 and G11739-302). Two anonymous reviewers gave valuable advice.

\section{REFERENCES}

Barnett T, Preisendorfer R. 1987. Origin and levels of monthly and seasonal forecast skill for United States surface air temperatures determined by canonical correlation analysis. Monthly Weather Review 115: 1825-1850.

Bengtsson L, Botzet M, Esch. M. 1995. Hurricane-type vortices in a general circulation model. Tellus 47A: 175-196.

Benestad R. 1998. SVD applied statistical downscaling for prediction of monthly mean land surface temperatures: model documentation. DNMI Report No. 30.

Busuioc A, von Storch H, Schnur R. 1999a. Verification of GCM generated regional seasonal precipitation for current climate and of statistical downscaling estimates under changing climate conditions. Journal of Climate 12: 258-272.

Busuioc A, Chen D, Hellström C. 1999b. Temporal and spatial variability of precipitation in Sweden over the 1890-1990 interval. Report C19, Earth Sciences Centre, University of Gothenburg, Sweden.

Cavazos T. 1999. Large-scale circulation anomalies conductive to extreme precipitation events and derivation of daily rainfall in northeastern Mexico and southeastern Texas. Journal of Climate 12: 1506-1523.

Chen D, Chen Y. 1999. Development and verification of a multiple regression downscaling model for monthly temperature in Sweden. In Preliminary Analysis and Statistical Downscaling of Monthly Temperature in Sweden, Report C16, Chen D, Hellström C, Chen Y (eds). Earth Sciences Centre, Göteborg University: Sweden; 41-55.

Chen D, Hellström C. 1999. The influence of the North Atlantic Oscillation on the regional temperature variability in Sweden: spatial and temporal variations. Tellus 51A: 505-516.

Cubasch U, von Storch H, Waskewitz J, Zorita E. 1996. Estimate of climate change in Southern Europe using different downscaling techniques. Climate Research 7: 129-149.

Fox-Rabinovitz MS, Stenchicov GL, Suarez MJ, Takacs LL. 1997. A finite difference GCM dynamical core with a variable resolution stretched grid. Monthly Weather Review 125: 2943-2968.

Frich F, Alexandersson H, Ashcroft J, Dahlström B, Demaree GR, Drebs A, van Engelen AFV, Forland EJ, Hanssen-Bauer I, Heino R, Jonsson T, Jonasson K, Keegan L, Nordli PO, Schmith T, Steffensen P, Tuomenvirta H, Tveito OE. 1996. North Atlantic Climatological Dataset (NACD Version 1) - Final Report. DNMI Report.

Giorgi F, Mearns L. 1991. Approaches to the simulation of regional climate change: a review. Review of Geophysics 29: 191-216.

Goodess C, Palutikof J. 1998. Development of daily rainfall scenarios for southeast Spain using a circulation-type approach to downscaling. International Journal of Climatology 10: 1051-1083.

Hulme M. 1994. Validation of large-scale precipitation fields in general circulation models. In Global Precipitation and Climate Change, NATO ASI series, vol. I26, Desbois M, Désalmand F (eds). Springer-Verlag: Berlin; 387-405.

Hurrell JW. 1995. Decadal trends in the North Atlantic Oscillation: regional temperatures and precipitation. Science 269: 676-679.

Johns TC. 1996. A description of the second Hadley Centre coupled model (HADCM2). Hadley Centre for climate prediction and research report No. 71 .

Johns TC, Carnell RE, Crossley JF, Gregory JM, Mitchell JFB, Senior CA, Tett SFB, Wood RA. 1997. The second Hadley Centre coupled atmosphere-ocean GCM: model description, spinup and validation. Climate Dynamics 13: 103-134.

Karl TR, Wang WC, Schlesinger ME, Knight RW, Portman D. 1990. A method of relating general circulation model simulated climate to the observed local climate. Part I: Seasonal statistics. Journal of Climate 1: 1057-1064.

Kharin V. 1995. The relationship between sea surface temperature anomalies and atmospheric circulation in GCM experiments. Climate Dynamics 11: 359-375.

Machenhauer BM, Windelbrand M, Botzet M, Christensen JH, Deque M, Jones RG, Ruti PM, Visconti G. 1998. Validation and analysis of regional present-day climate and simulation over Europe. MPI for Meteorology. Report No. 275.

Noguer M. 1994. Using statistical techniques to deduce local climate distributions. An application for model validation. Meteorological Applications 1: 277-287.

Palutikof JP, Winkler JA, Goodess CM, Andresen JA. 1997. The simulation of daily temperature time series from GCM output. Part 1: comparison of model data with observations. Journal of Climate 10: 2497-2513.

Ponater M, Köning W, Sausen R, Sielmann F. 1994. Circulation regime fluctuation and their effect on intraseasonal variability in the ECHAM climate model. Tellus 46A: 265-285.

Räisänen J, Döscher R. 1999. Simulation of present-day climate in Northern Europe in the HadCM2 GCM. Reports on Meteorology and Climatology, No. 48. Swedish Meteorological and Hydrological Institute.

Rummukainen M, Räisänen J, Ullerstig A, Bringfelt B, Hansson U, Graham P, Willen U. 1998. RAC-Rossby Centre regional atmospheric climate model: model description and results from the first multi-year simulation. SMHI RMK 83: 76. Obtainable from Swedish Meteorological and Hydrological Institute, Norrköping.

Trenberth KE, Paolino DA. 1980. The Northern Hemisphere sea-level pressure data set: trends, errors and discontinuites. Monthly Weather Review 108: 855-872.

von Storch H, Zorita E, Cubasch U. 1993. Downscaling of global climate change estimates to regional scale: An application to Iberian rainfall in wintertime. Journal of Climate 6: 1161-1171. 
von Storch H. 1995a. Spatial patterns: EOFs and CCA. In Analysis of Climate Variability: Application of Statistical Techniques, von Storch H, Navarra A (eds). Springer-Verlag: Berlin; 227-258.

von Storch H. 1995b. Inconsistencies at the interface of climate impacts studies and global climate research. Meteorologie Zeitschrift NF4: $72-80$.

Werner P, von Storch H. 1993. Interannual variability of Central European mean temperature in January-February and its relation to large-scale circulation. Climate Research 3: 195-207.

Wigley TML, Jones PD, Briffa KR, Smith G. 1990. Obtaining subgrid scale information from coarse-resolution general circulation model output. Journal of Geophysical Research 95: 1943-1953.

Zorita E, von Storch H. 1999. The analog method as a simple statistical downscaling technique: comparison with more complicated methods. Journal of Climate 12: 2474-2489. 